\title{
IAPs protect host target tissues from graft-versus-host disease in mice
}

\author{
Tomomi Toubai, ${ }^{1, \star}$ Corinne Rossi, ${ }^{1, *}$ Katherine Oravecz-Wilson, ${ }^{1}$ Chen Liu, ${ }^{2}$ Cynthia Zajac, ${ }^{1}$ Shin-Rong Julia Wu, ${ }^{1}$ Yaping Sun, ${ }^{1}$ \\ Hideaki Fujiwara, ${ }^{1}$ Hiroya Tamaki, ${ }^{3}$ Daniel Peltier, ${ }^{1}$ Mary Riwes, ${ }^{1}$ Israel Henig, ${ }^{1}$ Stuart Brabbs, ${ }^{1}$ Colin S. Duckett, ${ }^{4}$ Shaomeng Wang, ${ }^{1}$ and \\ Pavan Reddy ${ }^{1}$ \\ ${ }^{1}$ Division of Hematology and Oncology, Department of Internal Medicine, University of Michigan Comprehensive Cancer Center, Ann Arbor, Mi; ${ }^{2}$ Department of Pathology and \\ Laboratory Medicine, Rutgers-Robert Wood Johnson Medical School, New Brunswick, NJ; ${ }^{3}$ Division of Hematology, Department of Internal Medicine, Hyogo College of \\ Medicine, Hyogo, Japan; and ${ }^{4}$ Department of Pathology, University of Michigan Medical School, Ann Arbor, MI
}

\section{Key Points}

- IAP expression in hosts regulates GVHD.

-IAP expression in nonhematopoietic host targets is critical for mitigating GVHD damage.
Inhibitors of apoptosis proteins (IAPs) regulate apoptosis, but little is known about the role of IAPs in the regulation of immunity. Development of IAP inhibition by second mitochondriaderived activator of caspase (SMAC) mimetics is emerging as a novel therapeutic strategy to treat malignancies. We explored the role of IAPs in allogeneic immunity with 2 distinct yet complementary strategies, namely, chemical and genetic approaches, in clinically relevant models of experimental bone marrow transplantation (BMT). The small-molecule pan-IAP inhibitor SMAC mimetic AT-406 aggravated gastrointestinal graft-versus-host disease (GVHD) in multiple models. The role of specific IAPs in various host and donor cellular compartments was explored by utilizing X-linked IAP (XIAP)- and cellular IAP (cIAP)-deficient animals as donors or recipients. Donor T cells from C57BL/ $6 \mathrm{cIAP}^{-/-}$or XIAP ${ }^{-1-}$ animals demonstrated equivalent GVHD severity and allogeneic responses, both in vivo and in vitro, when compared with B6 wild-type (B6-WT) T cells. By contrast, when used as recipient animals, both $\mathrm{XIAP}^{-1-}$ and $\mathrm{CIAP} 1^{-1-}$ animals demonstrated increased mortality from GVHD when compared with B6-WT animals. BM chimera studies revealed that cIAP and XIAP deficiency in host nonhematopoietic target cells, but not in host hematopoietic-derived cells, is critical for exacerbation of GVHD. Intestinal epithelial cells from IAP-deficient animals showed reduced levels of antiapoptotic proteins as well as autophagy-related protein LC3 after allogeneic BMT. Collectively, our data highlight a novel immune cell-independent but target tissue-intrinsic role for IAPs in the regulation of gastrointestinal damage from GVHD.

\section{Introduction}

Inhibitors of apoptosis proteins (IAPs) regulate apoptosis, and recent data suggest that they play an important role in both innate and adaptive immunity ${ }^{1-3}$ through diverse mechanism seyond the inhibition of caspases. ${ }^{4}$ Among IAPs, X-linked IAP (XIAP), cellular IAP1 (cIAP1), and cIAP2 regulate the production of proinflammatory cytokines and the activation of $T$ cells and antigen-presenting cells (APCs) through the modulation of MAPK and nuclear factor $\kappa B$ (NF- $\mathrm{B}$ ) signaling pathways. ${ }^{1,5}$ In addition, genetic mutations and IAP deficiencies are associated with congenital immunodeficiency disorders, such as $\mathrm{X}$-linked lymphoproliferative disease type 2 and familial hemophagocytic lymphohistiocytosis in humans. ${ }^{6,7}$ XIAP deficiency has also been associated with inflammatory bowel disease (IBD). ${ }^{8}$

Because IAPs are highly expressed in solid cancers and associated with tumor progression, resistance to chemotherapy, and poor prognosis, small-molecule IAP antagonists are under clinical development for the treatment of solid and hematological malignancies. ${ }^{9-11}$ These are known as second mitochondria-derived
Submitted 3 January 2017; accepted 1 July 2017. DOI 10.1182/ bloodadvances.2017004242.

*T.T. and C.R. contributed equally to this study.
The full-text version of this article contains a data supplement. (C) 2017 by The American Society of Hematology 
activator of caspase (SMAC) mimetics. $^{9-11}$ All IAPs contain baculovirus IAP repeat (BIR) domains and a carboxy-terminal RING finger domain and inhibit caspases. ${ }^{12-15}$ Cell-intrinsic SMACs bind to IAPs at BIR3 domains. SMAC mimetics interfere with this interaction and thus modulate IAP function and apoptosis. SMAC mimetics also promote degradation of IAPs (especially cIAP), resulting in activation of noncanonical NF-кB pathway. ${ }^{12,13,16-18}$ The cytotoxic killing induced by SMAC mimetics might be associated with a simultaneous secretion of autocrine/paracrine tumor necrosis factor $\alpha(T N F \alpha)$ or TNF receptor 1 (TNFR1)-induced cell signaling. ${ }^{16,17,19}$ These findings are consistent with the notion that SMAC mimetics may promote inflammation because both XIAP and cIAP negatively regulate inflammation through the inhibition of TNFR1-dependent proinflammatory cytokine production or NLRP3 inflammasome activation in myeloid cells. ${ }^{20-22}$ In contrast, SMAC mimetic treatment has also been shown to attenuate inflammatory responses by blunting leukocyte infiltration ${ }^{23}$ or by inhibiting macrophages. ${ }^{24}$ These data indicate that SMAC mimetics may have conflicting effects on the modulation of inflammatory responses under different circumstances.

Allogeneic hematopoietic stem-cell transplantation (allo-HCT) is a potentially curative treatment modality for a number of malignant hematologic disorders. It is characterized by conditioning-related as well as allogeneic reactivity-induced inflammations that cause its major complication, acute graft-versus-host disease (GVHD). ${ }^{25}$ The proinflammatory cytokines activate both host- and donor-derived APCs that stimulate allogeneic reactive donor T cells, which migrate to the gastrointestinal (GI) tract, liver, and skin and cause GVHD that is characterized by target-cell apoptosis. ${ }^{26-29}$ Despite the increasing appreciation of the role of targeting IAPs in immunity and malignancies, their role in T-cell allogeneic immunity, APC responses, and response of target tissues to immune-mediated attack in GVHD remains unknown.

In the present study we determined the role of IAPs in GVHD by utilizing clinically relevant, well-characterized murine models of allogeneic bone marrow transplantation (allo-BMT). To chemically target IAPs, we used AT-406 (SM-406), an SMAC mimetic that actively antagonizes all IAPs (XIAP and cIAPs) ${ }^{30}$ in vitro and in vivo. ${ }^{31}$ AT-406 is an orally bioavailable SMAC mimetic and is being currently investigated in phase I clinical trials for the treatment of human solid cancers and hematological malignancies. ${ }^{32,33}$ In addition, as a genetic approach, we used cIAP1/XIAP knockout

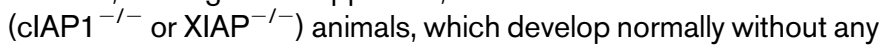
inflammation in steady state. ${ }^{1,2,15}$ We found that global inhibition of IAPs exacerbated experimental GVHD, and the critical cellular component that aggravated the severity of GVHD resulted from the absence of IAPs in target tissues and not from their effects on donor or host immune cells. Our data thus suggest a role for target tissue-intrinsic programs that can mitigate GVHD without directly altering the functionality of immune cells.

\section{Materials and methods}

\section{Mice}

C57BL/6 (B6, H-2 $\left.{ }^{\mathrm{b}}, \mathrm{CD} 45.2^{+}\right), \mathrm{B} 6 \mathrm{D} 2 \mathrm{~F} 1\left(\mathrm{H}-2^{\mathrm{b} / \mathrm{d}}\right)$, and C3H.sw $\left(\mathrm{H}-2^{\mathrm{b}}\right)$ mice were purchased from the Jackson Laboratory (Bar Harbor, ME). BALB/c $\left(H-2^{d}\right)$ mice were purchased from Charles River Laboratories (Wilmington, MA). B6Ly5.2 ( $\left.\mathrm{H}-2^{\mathrm{b}}, \mathrm{CD} 45.1^{+}\right)$mice were purchased from National Cancer Institute Frederick (Frederick, MD). B6background $\mathrm{cIAP}^{-1-}$ and $\mathrm{XIAP}^{-1-}$ animals were provided by C.S.D. and have been described previously. ${ }^{15}$ All animals were cared for according to regulations reviewed and approved by the University Committee on Use and Care of Animals of the University of Michigan, based on University Laboratory Animal Medicine guidelines.

\section{Reagents}

The SMAC mimetic SM-164 (AT-406) ${ }^{30}$ was a kind gift from Shaomeng Wang (University of Michigan).

\section{Generation of BM chimeras}

BM chimeras (B6 $\rightarrow \mathrm{B} 6$ Ly5.2, clAP1 ${ }^{-1-} \rightarrow \mathrm{B} 6$ Ly5.2, XIAP ${ }^{-1-} \rightarrow \mathrm{B} 6$ Ly5.2) were generated as described previously. ${ }^{34-37}$ Briefly, B6 Ly5.2 animals received 11-Gy total-body irradiation ( $\mathrm{TBl}$; caesium-137 source) on day -1 and received transplants IV of $5 \times 10^{6} \mathrm{BM}$ and $5 \times 10^{6}$ whole spleen cells from $\mathrm{B} 6$ wild-type (B6-WT) or $\mathrm{clAP}^{-1-}$ or $\mathrm{XIAP}^{-1-}$ donor animals on day 0. To generate B6 Ly5.2 $\rightarrow \mathrm{B} 6$, B6 Ly5.2 $\rightarrow \mathrm{ClAP}^{-/-}$, and B6 Ly5.2 $\rightarrow \mathrm{XIAP}^{-1-}$ chimeras, B6-WT or $\mathrm{CIAP}^{-1-}$ or $\mathrm{XIAP}^{-1-}$ animals received $10-\mathrm{Gy} \mathrm{TBI}$ on day -1 and received transplants of $5 \times 10^{6} \mathrm{BM}$ and $5 \times 10^{6}$ whole spleen cells from WT B6 Ly5.2 donor animals on day 0. Donor hematopoietic cell engraftment was confirmed using the CD45.2 or CD45.1 monoclonal antibody 3 to 4 months after BMT (donor type $>95.0 \%$ ).

\section{BMT and treatment of AT-406}

BMTs were performed as previously described. ${ }^{34,35,38}$ Briefly, splenic T cells from donors were purified, and the BM was depleted of $\mathrm{T}$ cells by autoMACS (Miltenyi Biotec, Bergisch Gladbach, Germany) utilizing CD90.2 microbeads (Miltenyi Biotec). We used well-established multiple BMT models. B6, BALB/c, B6D2F1, and $\mathrm{C} 3 \mathrm{H} . \mathrm{sw}$ animals were used as recipients and received either 8.5 (BALB/c), 10 (B6), 10.5 (C3H.sw), or 11 Gy (B6D2F1; caesium137 source) on day -1 and 0.5 to $1.0 \times 10^{6}(\mathrm{~B} 6 \rightarrow \mathrm{BALB} / \mathrm{c})$, $2 \times 10^{6}(\mathrm{C} 3 \mathrm{H} . \mathrm{sw} \rightarrow \mathrm{B} 6)$, and $3 \times 10^{6}(\mathrm{~B} 6 \rightarrow \mathrm{B} 6 \mathrm{D} 2 \mathrm{~F} 1) \mathrm{CD} 90.2^{+}$ T cells along with $5 \times 10^{6} \mathrm{~T}$ cell-depleted BM (TCD-BM) cells from either syngeneic or allogeneic donors on day 0 . For the treatment of AT-406, AT-406 $(10 \mathrm{mg} / \mathrm{kg})$ and its diluent control phosphatebuffered saline (PBS) were administered by subcutaneous injection at days $-1,+1,+3,+5$, and +7 .

\section{Systemic and histopathological analysis of GVHD}

We monitored survival after allo-HCT daily and assessed the degree of clinical GVHD weekly, as described previously. ${ }^{39}$ Histopathological analysis of the liver, Gl tract, and lung, which are the primary GVHD target organs, was performed as described ${ }^{40}$ utilizing a semiquantitative scoring system implemented by a single pathologist (C.L.). ${ }^{40}$ After scoring, the codes were broken, and the data were compiled.

\section{DC cultures}

To obtain dendritic cells (DCs), BM cells from B6-WT or BALB/c animals were cultured with murine recombinant granulocytemacrophage colony-stimulating factor (20 ng/mL; PeproTech, Rocky Mill, NJ) for 7 days and harvested as described previously. ${ }^{37}$ DCs were isolated by using CD11c (N418) MicroBeads (Miltenyi Biotec) and the autoMACS (Miltenyi Biotec) and used as a stimulator for mixed lymphocyte reaction (MLR).

\section{FACS analysis}

Fluorescence-activated cell sorting (FACS) analyses were performed as previously described. ${ }^{37,41}$ Briefly, to analyze donor T-cell expansion 
and activation markers, splenocytes, hepatic lymphocytes, ${ }^{42}$ and intraepithelial lymphocytes ${ }^{43}$ from transplant-recipient mice were resuspended in FACS wash buffer (2\% bovine serum albumin in $\mathrm{PBS}$ ) and stained with conjugated monoclonal antibodies (mAbs): fluorescein isothiocyanate (FITC)-conjugated mAbs to mouse $\mathrm{H}_{2} \mathrm{~K}^{\mathrm{d}}$ (clone SF1-1.1) and $\mathrm{H}_{2} \mathrm{~K}^{\mathrm{b}}$ (clone AF6-88.5); PerCP-Cy5.5conjugated mAbs to mouse CD4 (clone GK1.5) and CD8 (clone 53-6.7); phycoerythrin (PE)-conjugated mAbs to mouse CD69 (clone H1.2F3), CD183 (CXCR3; clone CXCR3-173), LPAM-1 (integrin $\alpha 4 \beta 7$; clone DATK32), and CD62L (clone MEL-14); and APCconjugated mAbs to mouse CD44 (clone IM7; BioLegend, San Diego, CA). After staining, the cells were washed twice and fixed with $2 \%$ formaldehyde. The procedure was performed as described previously. ${ }^{37}$ Cells were analyzed using a BD Accuri C6 flow cytometer (BD Bioscience, San Diego, CA). For intracellular staining to detect cytokines, cells were permeabilized after fixation and stained with PE-conjugated interferon $\gamma$ (IFN- $\gamma$; clone XMG1.2), interleukin-2 (IL-2; clone JES6-5H4), and Foxp3 (clone MF-14) and APCconjugated mAbs to mouse TNF- $\alpha$ (clone MP6-XT22) and IL-17A (clone TC11-18H10.1; BioLegend) according to manufacturer protocol. For intracellular staining to detect cIAP1, XIAP, BCL-2, BIM, BAX, and LC3, cells were fixed with $2 \%$ formaldehyde and permeabilized with BDPhosFlow (BD Bioscience) and then stained with FITC-conjugated polyclonal Abs to mouse BIM (orb15184) and $\mathrm{BAX}$ (orb7603) from Biorbyt (Berkeley, CA) and PE-conjugated mAbs to mouse BCL-2 (clone BCL/10C4; BioLegend). In the case of nonconjugated Abs, firstly, gout polyclonal Ab, anti-clAP1(D-19, sc1869), and rabbit polyclonal anti-XIAP (H-202, sc-11426; Santa Cruz Biotechnology, Dallas, TX) and anti-LC3B/MAP1LC3B (NB100-2220; Novus Biotechnology, Littleton, CO) were stained, and appropriate secondary antibodies were used to detect these expressions.

\section{MLR}

Splenic T cells from B6-WT, cIAP $1^{-1-}$, or $\mathrm{XIAP}^{-1-}$ animals (magnetically separated by MACS using CD90.2 microbeads) were used as responders and BALB/C- versus B6-WT-derived BM-derived DCs (BMDCs) were used as stimulators in an MLR. $1 \times 10^{5} \mathrm{~T}$ cells and irradiated (20 Gy) $2.5 \times 10^{3}$ BMDCs were cocultured on 96-well U-bottom plates for 96 hours. The incorporation of ${ }^{3} \mathrm{H}$-thymidine ( $1 \mu \mathrm{Ci}$ per well) by proliferating $\mathrm{T}$ cells during the final 16 hours of coculture was measured by a Betaplate reader (Wallad, Turku, Finland). In some experiments, BMDCs were pretreated with AT-406 $(1 \mu \mathrm{M})$ for 6 hours and then used as a stimulator, or AT-406 $(1 \mu \mathrm{M})$ and its diluent control were added in culture wells during reaction.

\section{Nonspecific T-cell receptor stimulation}

Isolated $\mathrm{T}$ cells $\left(1 \times 10^{5}\right.$ per well) from B6-WT, clAP1 ${ }^{-1-}$, or $\mathrm{XIAP}^{-1-}$ animals (magnetically separated by MACS using CD90.2 microbeads) were stimulated with anti-CD3 $(2 \mu \mathrm{g} / \mathrm{mL})$ and CD28 $(1 \mu \mathrm{g} / \mathrm{mL})$ antibodies in the presence or absence of AT-406 $(1 \mu \mathrm{M})$ on 96 -well U-bottom plates for 24 or 48 hours. The incorporation of ${ }^{3} \mathrm{H}$-thymidine $(1 \mu \mathrm{Ci}$ per well) by proliferating $\mathrm{T}$ cells during the final 6 hours of culture was measured by a Betaplate reader (Wallad).

\section{DC stimulation by pathogen- and damage-associated molecular patterns}

BMDCs were stimulated with lipopolysaccharide (500 ng/mL), proteoglycan (5 $\mathrm{g} / \mathrm{mL}$ ), Pam3CSK4 (300 ng/mL), and HMGB1
$(10 \mu \mathrm{g} / \mathrm{mL})$ for 16 hours, and then supernatants were collected and DCs harvested and stained with conjugated mAbs to test the expression of costimulatory molecules: FITC-conjugated mAbs to mouse CD11c (clone N418) and PE-conjugated mAbs to mouse CD80 (clone 16-10A1), CD86 (clone GL-1), CD40 (clone 3/23), B7H1 (PDL-1, clone 10F.9G2), and I-Ab (AF6-120.1; BioLegend). Cells were analyzed using a BD Accuri C6 flow cytometer (BD Bioscience).

\section{Cytokine ELISA}

Concentrations of IFN- $\gamma$, TNF- $\alpha$, IL-17A, and IL- 6 were measured in the serum or culture supernatants by enzyme-linked immunosorbent assay (ELISA) with specific anti-mouse mAbs for capture and detection utilizing BD OptEIA (IFN- $\gamma$, IL-6; BD Bioscience), ELISA MAX (IL-17A; BioLegend), or Mouse TNF- $\alpha$ Quantikine ELISA Kit (R\&D Systems, Minneapolis, MN). Assays were performed according to manufacturer protocol and read at $450 \mathrm{~nm}$ using a microplate reader (Model 3550; Bio-Rad Labs, Hercules, CA). All samples and standards were run in duplicate.

\section{Apoptosis analysis}

Non-T-cell receptor-stimulated $T$ cells were washed twice with PBS and stained with a PE-conjugated anti-annexin $\mathrm{V}$ mAb (BioLegend) and PerCP-Cy5.5-conjugated anti-90.2 mAb (BioLegend) in the dark for 15 minutes at room temperature in labeling buffer and analyzed using an Accuri C6 cytometer (Accuri, Ann Arbor, MI).

Regarding epithelial cell isolation, small intestines and colons were digested once with $0.1-\mathrm{mM}$ EDTA at $37^{\circ} \mathrm{C}$ for 45 minutes.

\section{Western blot analysis}

Epithelial cells of the small intestine were isolated as described above, and whole cells were lysed in RIPA lysis extraction buffer (Thermo Scientific, Rockford, IL). Equal amounts of protein lysates quantified with the BCA Protein Assay Kit (Thermo Scientific) were separated with $10 \%$ sodium dodecyl sulfate polyacrylamide gel electrophoresis. Rabbit LC3 antibody (Novus Biologicals, Littelton, $\mathrm{CO})$ was used according to manufacturer instructions. Secondary antibody conjugated to horseradish peroxidase (Jackson Immunoresearch) was used to detect the primary antibody. Densitometric analysis was performed using ImageJ software.

\section{TUNEL staining}

Histopathological samples of the small and large intestines were harvested at day 7 after BMT and fixed with paraffin. Terminal deoxynucleotidyl transferase dUTP nick end labeling (TUNEL) staining was performed with the In Situ Cell Death Detection Kit, AP (Roche, Basel, Switzerland) according to manufacturer instructions. Briefly, tissues were dewaxed and rehydrated with 2 washes in xylene $100 \%$ followed by serial washes in decreasing concentrations of ethanol in water (100\% to $95 \%-75 \%$ to $50 \%-10 \%$ to $0 \%$ ). Proteinase $\mathrm{K}$ at a concentration of $20 \mu \mathrm{g} / \mathrm{mL}$ was incubated for 30 minutes at $37^{\circ} \mathrm{C}$. After washes, the TUNEL reaction mix was incubated for 60 minutes at $37^{\circ} \mathrm{C}$, followed by the AP converter for 30 minutes at $37^{\circ} \mathrm{C}$. A negative control was incubated with the label solution of the reaction mix only. A positive control was pretreated with a DNase recombinant. A nucleus counterstain was then used. At the end of the procedure, the tissues were mounted on a 9:1 ratio of glycerol toPBS, and representative pictures were taken. 


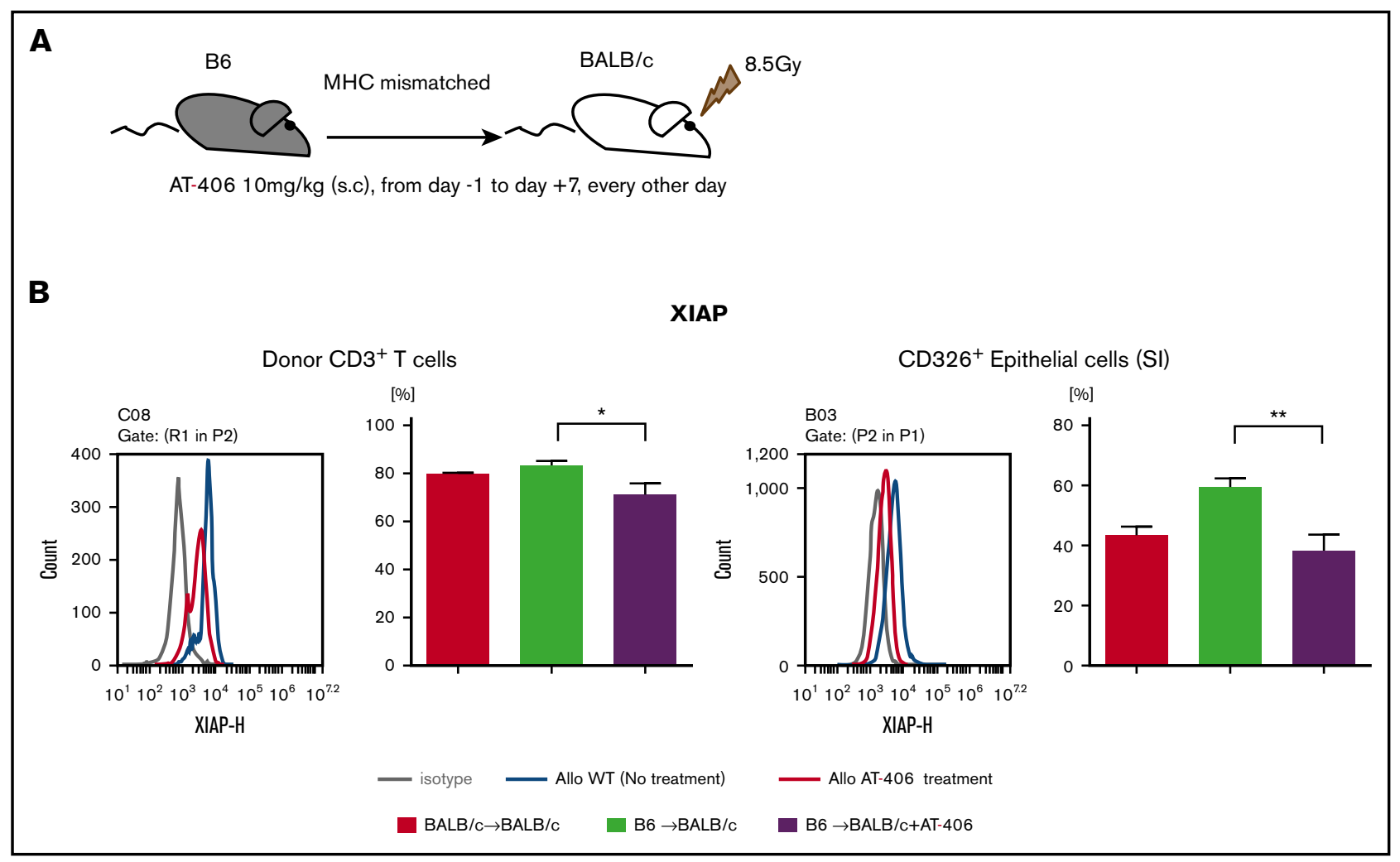

Figure 1. AT-406 decreases the expression of XIAP in donor T cells and host nonhematopoietic target cells after allo-BMT. (A-B) BALB/c animals received 8.5 Gy on day -1 and received transplants of $0.5 \times 10^{6} \mathrm{CD} 90.2^{+}$splenic T cells along with $5 \times 10^{6} \mathrm{TCD}-\mathrm{BM}$ cells from either syngeneic BALB/c or allogeneic MHC-mismatched B6 donors. Recipient animals received either AT-406 $(10 \mathrm{mg} / \mathrm{kg})$ or its diluent subcutaneously on days $-1,+1,+3,+5$, and +7 after BMT. (A) Schema of experiment. (B) XIAP expression of donor $\mathrm{CD}^{+} \mathrm{T}$ cells in the spleen and $\mathrm{CD} 326^{+}$epithelial cells of the small intestine was evaluated by FACS staining on day 8 . Representative figure (left) and pooled data (right) from 5 to 8 animals are shown. ${ }^{\star} P<.05,{ }^{\star \star} P<.01$. The bar shows the mean \pm standard error of the mean (SEM).

\section{Statistical analysis}

The Mann-Whitney $U$ test was used for the statistical analysis of in vitro data, and the Wilcoxon rank test was used to analyze survival data. A $P$ value $<.05$ was considered to be statistically significant.

\section{Results}

\section{IAP inhibitor exacerbates GVHD responses}

IAPs are broadly expressed in immune cells, such as T cells and APCs as well as parenchymal cells, and play an important role in regulating innate and adaptive immune responses. ${ }^{2,44}$ IAPs regulate TNF- $\alpha$ and NF-kB activation. ${ }^{45,46}$ Because the pan-IAP inhibitor AT-406, an SMAC mimetic, regulates TNF $\alpha,{ }^{47}$ one of the most important cytokines mediating GVHD, ${ }^{48}$ and shows good bioavailability in vivo, ${ }^{30,49,50}$ we tested the hypothesis that administration of AT-406 would mitigate GVHD. On the basis of its half-life, we first tested various dosing regimens of AT-406 to determine the optimal dose for targeting IAPS after allo-BMT. In the lethally irradiated major histocompatibility complex (MHC)-mismatched B6-into-BALB/c model, the dose of $10 \mathrm{mg} / \mathrm{kg}$ from day -1 to day 7 , every other day of AT-406 consistently targeted XIAP in donor T cells and host nonhematopoietic target cells (CD326 ${ }^{+}$ intestinal epithelial cells [IECs]; Figure 1A-B). Similar results were also observed for cIAP (supplemental Figure 1).

Next, we used the above dose and schedule regimen to evaluate the impact of AT-406 on the regulation of allogeneic immune responses and the severity of GVHD in the same MHC-mismatched B6-into-BALB/C BMT model. Recipient BALB/c animals were irradiated with 8.5 Gy on day -1 and received transplants of $0.5 \times$ $10^{6} \mathrm{~T}$ cells along with $5 \times 10^{6} \mathrm{TCD}-\mathrm{BM}$ cells from either syngeneic $\mathrm{BALB} / \mathrm{c}$ or allogeneic MHC-mismatched B6 donors. Both groups received either AT-406 or its diluent. As shown in Figure $2 A$, all the syngeneic mice that received AT-406 or diluent survived, thus ruling out nonspecific toxicity from AT-406. However, contrary to our hypothesis, allogeneic animals that received AT-406 showed significantly worse GVHD and died more rapidly than control B6-WT animals $(P=.0012$; Figure $2 \mathrm{~A})$.

To eliminate strain-dependent factors, we used another wellestablished MHC-mismatched haploidentical B6-into-B6D2F1 model of BMT. Recipient B6D2F1 animals received 11 Gy on day -1 and received transplants of $3 \times 10^{6} \mathrm{~T}$ cells along with $5 \times 10^{6}$ TCD-BM cells from either syngeneic B6D2F1 or allogeneic MHCmismatched $\mathrm{B} 6$ donors. Both groups received the same treatment as above. Allogeneic B6D2F1 recipients treated with AT-406 showed significantly greater GVHD severity and mortality $(P=.012$; Figure 2B).

We next explored whether the enhanced GVHD in the allogeneic animals that were treated with AT-406 was associated enhanced donor T-cell expansion and cytokine secretion when compared with control-treated allogeneic animals on day 7 after BMT. There was no significantly greater expansion of total donor $\mathrm{T}$ cells or donor 

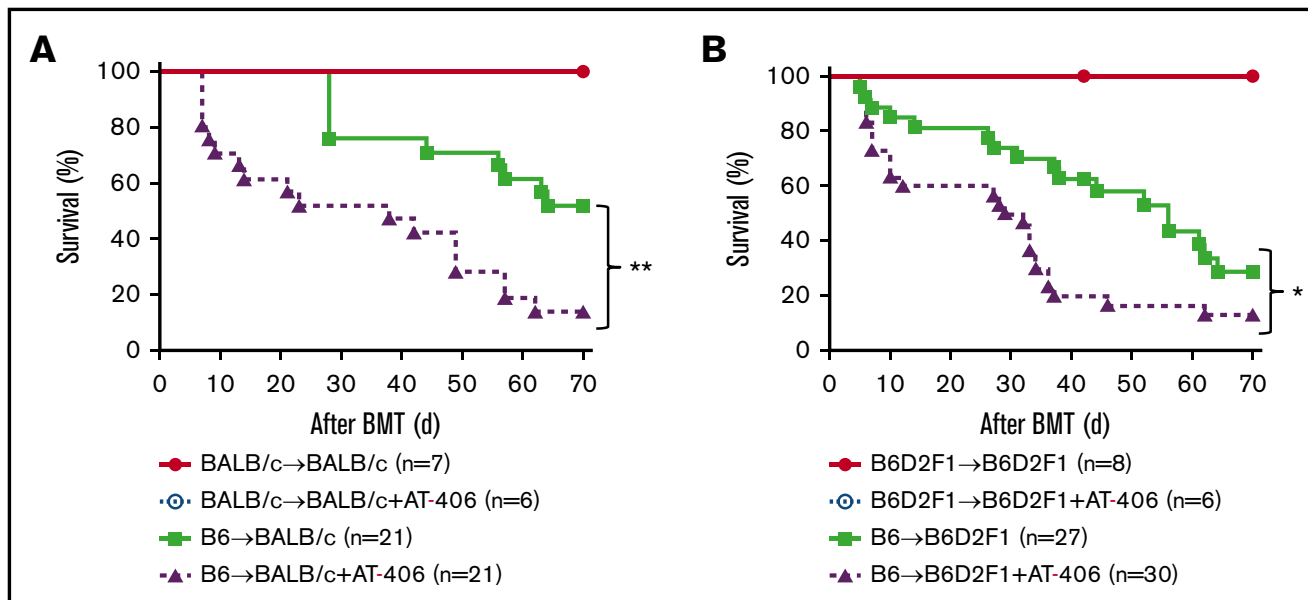

C
Donor $\mathrm{T}$ cell expansion (Day 6)

D

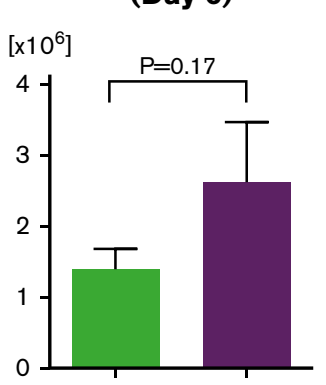

\section{Donor CD44 ${ }^{+}$CD62L- T cells (Day 6)}

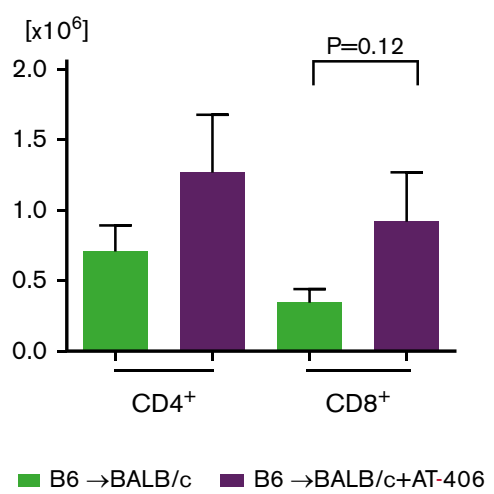

E
Donor IFN- $\gamma^{+} \mathbf{T}$ cells (Day 6)

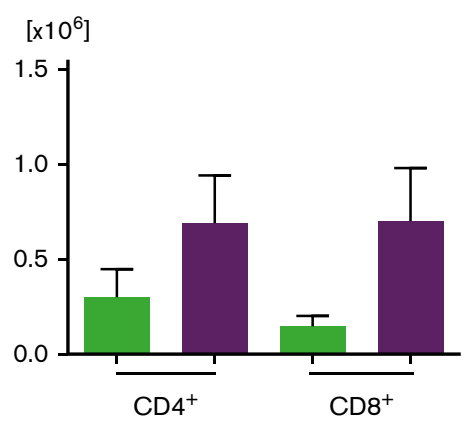

$\mathbf{F}$

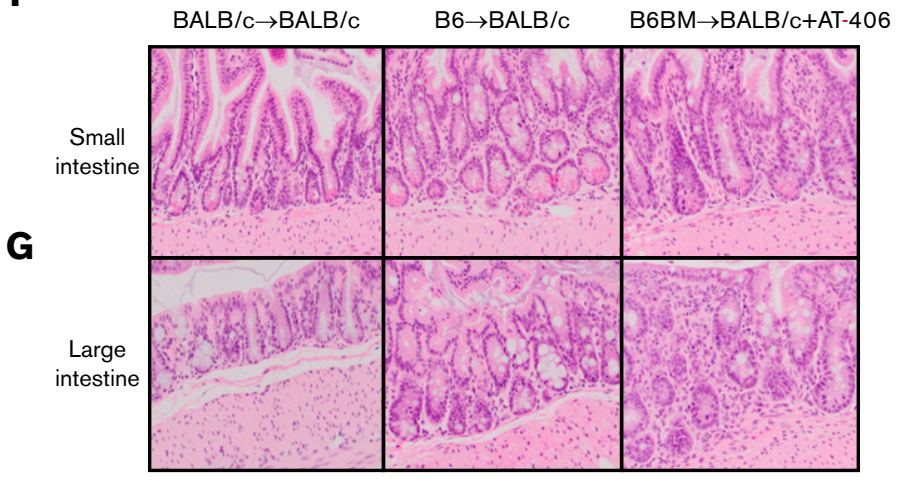

H

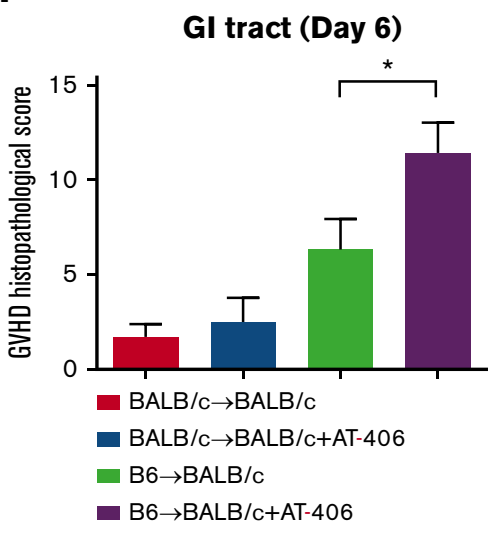

Figure 2. The IAP inhibitor AT-406, an SMAC mimetic, exacerbates GVHD. (A) Survival. BALB/c animals received 8.5 Gy on day -1 and received transplants of $0.5 \times 10^{6}$ CD90.2 ${ }^{+}$splenic T cells along with $5 \times 10^{6}$ TCD-BM cells from either syngeneic BALB/c or allogeneic MHC-mismatched B6 donors. Recipient animals received either AT-406 $(10 \mathrm{mg} / \mathrm{kg})$ or its diluent subcutaneously on days $-1,+1,+3,+5$, and +7 after BMT; $n=6-21$ per group). Pooled data from 4 independent experiments are shown. ${ }^{\star \star} P<.01$, when allogeneic treated and control animals are compared. (B) Survival. B6D2F1 animals received 11 Gy on day -1 and received transplants of $3 \times 10^{6}$ CD $90.2^{+}$ splenic T cells along with $5 \times 10^{6} \mathrm{TCD}-\mathrm{BM}$ cells from either syngeneic B6D2F1 or allogeneic MHC-mismatched haploidentical B6 donors. Recipient animals received either AT-406 $(10 \mathrm{mg} / \mathrm{kg})$ or its diluent subcutaneously on days $-1,+1,+3,+5$, and +7 after BMT ( $n=6-30$ per group). Pooled data from 6 independent experiments are shown. ${ }^{*} P<.05$, when allogeneic treated and control animals are compared. (C-E) Expansion of donor T cells $\left(\mathrm{H}-2 \mathrm{k}^{\mathrm{b}+} \mathrm{CD}^{+} \mathrm{CD} 8^{+}\right)(\mathrm{C}), \mathrm{CD}_{4} 4^{+} \mathrm{CD} 62 \mathrm{~L}^{-}$effector T cells $(\mathrm{D})$, and IFN- $\gamma$-producing T cells $(E)$ in the spleen on day 6 after allo-BMT ( $n=4-5$ per group, pooled from 2 experiments). The bar shows the mean \pm SEM. (F-H) The representative figures of small $(F)$ and large intestines $(G)$ (original magnification $\times 200$; hematoxylin and eosin stain) and GVHD histopathological score of Gl tract (small and large intestines) $(\mathrm{H})$ on day 6 after allo-BMT ( $n=6-10$ per group, pooled from 3 experiments). ${ }^{*} P<.05$. The bar shows the mean \pm SEM. 
CD44 ${ }^{+} \mathrm{CD}_{2} \mathrm{~L}^{-}$effector $\mathrm{T}$ cells or proinflammatory cytokine secretion from splenic donor $T$ cells (Figure 2C-E; supplemental Figure 2A-C). However, the GVHD-specific histopathological damage of the Gl tract was substantially worse in AT-406-treated animals (Figure 2F-H). To clarify whether AT-406 exacerbates irradiation toxicity in the gut, we also tested the histopathological damage in the gut in syngeneic animals with AT-406 treatment and found that histopathological damage in these animals was comparable to that in WT syngeneic animals (Figure $2 \mathrm{H}$ ). These data suggest that AT-406 exacerbated Gl damage from GVHD in multiple BMT models.

\section{IAPs in T cells are not required for enhancing GVHD severity}

Donor $\mathrm{T}$ cells are indispensable to GVHD. ${ }^{51}$ Therefore, we next explored whether the augmentation of GVHD severity by the systemically administered AT-406 resulted from inhibition of IAPs on donor $\mathrm{T}$ cells. To dissect the cellular components, we took a genetic approach. To this end, we used 2 genetically deficient IAP animals, namely, XIAP and cIAP1 knockout animals. The role of IAPs in T-cell responses seems to be context dependent. ${ }^{52,53} \mathrm{We}$ first examined the absolute numbers of $\mathrm{CD}^{+}$and $\mathrm{CD}^{+}{ }^{+}$cells and then determined detailed phenotypes of various $\mathrm{T}$-cell subsets and the expression of the activation marker in naïve B6-WT, B6-clAP1 ${ }^{-1-}$, and $\mathrm{B} 6-\mathrm{XIAP}^{-1-}$ animals. We found similar numbers of $\mathrm{CD} 4^{+}$ and $\mathrm{CD}^{+} \mathrm{T}$ cells (supplemental Figure $3 \mathrm{~A}$ ) and an equivalent distribution of naïve $\left(\mathrm{CD} 44^{-} \mathrm{CD}_{2} \mathrm{~L}^{+}\right)$, central memory $\left(\mathrm{CD} 44^{+}\right.$ $\left.\mathrm{CD} 62 \mathrm{~L}^{+}\right)$, effector memory $\left(\mathrm{CD} 44^{+} \mathrm{CD} 62 \mathrm{~L}^{-}\right)$, and regulatory $\left(\mathrm{CD} 4^{+} \mathrm{CD} 25^{+} \mathrm{Foxp}^{+}\right) \mathrm{T}$ cells in all 3 mouse strains (supplemental Figure 3B-D).

We next explored whether IAPs in donor T cells have a critical role in the aggravation of GVHD responses in vivo. We used the $\mathrm{MHC}$ completely mismatched B6-into-BALB/c model. B6-WT, XIAP ${ }^{-1-}$, or clAP1 ${ }^{-1-}$ splenic $T$ cells were used as sources of donor $T$ cells, but the TCD-BM was obtained from B6-WT animals such that only the differences in the infused mature naïve $T$ cells could be evaluated for their effect on GVHD. Recipient BALB/c animals were irradiated with 8 Gy on day -1 and received transplants of $0.5 \times$ $10^{6} \mathrm{~T}$ cells as above along with $5 \times 10^{6} \mathrm{TCD}-\mathrm{BM}$ cells from either syngeneic BALB/c or allogeneic MHC-mismatched $\mathrm{B} 6$ donors. We found that all of the allogeneic recipients showed similar GVHD severity and mortality regardless of whether they received $T$ cells from WT or XIAP ${ }^{-1-}$ or clAP1 ${ }^{-1-}$ animals (Figure $3 \mathrm{~A}-\mathrm{B}$ ). The role of XIAP and cIAP1 in donor T cells was next determined in a second, lethally irradiated MHC-mismatched haploidentical B6-intoB6D2F1 model. Recipient B6D2F1 animals received 11 Gy on day -1 and received transplants of $3 \times 10^{6} \mathrm{~T}$ cells along with $5 \times$ $10^{6}$ TCD-BM cells from either syngeneic B6D2F1 or allogeneic $\mathrm{MHC}$-mismatched $\mathrm{B} 6$ donors. Donor WT, $\mathrm{XIAP}^{-1-}$, and $\mathrm{ClAP} 1^{-1-}$ T cells induced equivalent GVHD severity and mortality (Figure $3 C$ ). The similar GVH responses were confirmed by equivalent donor T-cell expansion (Figure 3D), activation (Figure 3E), and IFN- $\gamma$ secretion (Figure $3 F$ ) in the spleen 14 days after BMT. The GVHD-specific histopathological damage of the Gl tract and liver on day 14 was also equivalent among these groups (Figure $3 \mathrm{G}-\mathrm{H}$ ).

To further determine whether there were any $\mathrm{T}$ cell-intrinsic differences in response to allogeneic stimulus, we also determined in vitro whether $\mathrm{XIAP}^{-1-}$ and $\mathrm{clAP}^{-1-} \mathrm{T}$ cells showed any differences when compared with WT T cells in the presence or absence of the SMAC mimetic AT-406. Stimulation of WT T cells with allogeneic BALB/c-derived BMDCs in an MLR showed no significant differences in T-cell proliferation regardless of presence of AT-406 (Figure 3l). Furthermore, the WT, $\mathrm{XIAP}^{-1-}$, and $\mathrm{cIAP}^{-1-} \mathrm{T}$ cells showed a similar proliferation and secretion of IFN- $\gamma$ and IL-2 after stimulation with allogeneic MLR in both the presence and absence of AT-406 (Figure 3J; supplemental Figure 4A-B). However, we found that AT-406 augmented nonspecific T-cell receptor responses when stimulated with anti-CD3/28 in vitro, as shown in a previous report (supplemental Figure 4C) ${ }^{53}$ Collectively, these results demonstrate that the inhibition of IAPs or the expression of XIAP1 or clAP1 in donor T cells plays a dispensable role in allogeneic T-cell responses, especially GVHD.

\section{IAPs in host animals mitigate GVHD}

We next reasoned that the inhibition of IAPs in host tissues might be driving the exacerbation of GVHD after treatment with SMAC mimetics. To test this, we first examined whether the IAP levels in the IECs $\left(\mathrm{CD} 326^{+}\right)$were altered after irradiation to eliminate radiation-dependent confounding factors. We found that IAP levels in $\mathrm{CD}_{2} 6^{+}$cells were transiently decreased at 24 hours after irradiation but spontaneously recovered in 48 hours (supplemental Figure $5 \mathrm{~A}-\mathrm{B}$ ). We next explored whether IAP deficiency had an impact on the radiation toxicity in an intensity-dependent manner; B6-WT, $\mathrm{XIAP}^{-1-}, \mathrm{clAP}^{-1-}$ animals received 9, 13, and 15 Gy on day -1 and received transplants of $5 \times 10^{6} \mathrm{BM}$ cells and $3 \times 10^{6}$ splenic $T$ cells from syngeneic B6 animals. We found that the overall survival of IAP-deficient animals was comparable to that of WT animals even with increased radiation dose (supplemental Figure 5C-E). In addition, histopathological damage in IAP-deficient animals was comparable to that in B6-WT animals after irradiation (supplemental Figure 5F). These data suggest that change in IAP expression in the $\mathrm{CD}_{2} 26^{+}$cells because of radiation toxicity may have had a negligible role in our BMT models. Next, we used $\mathrm{XIAP}^{-/-}$animals as recipients of allo-BMT. Recipient B6-WT and $\mathrm{B} 6-\mathrm{XIAP}^{-1-}$ animals were lethally irradiated and received transplants on day 0 of $5 \times 10^{6}$ TCD-BM cells and $3 \times 10^{6}$ splenic CD90.2 $2^{+}$T cells from either syngeneic B6-WT or allogeneic MHCmismatched BALB/c donors. As shown in Figure $4 A$, all the syngeneic $B 6-W T$ and $B 6$ XIAP $^{-1-}$ animals survived the period of observation, ruling out any significant effect of conditioning-related damage on survival after BMT. By contrast, allogeneic B6-XIAP ${ }^{-1-}$ animals showed significantly worse survival and clinical GVHD severity than B6-WT animals ( $P=.0003$; Figure 4A; supplemental Figure 6A). However, the increased mortality was associated neither with an increased donor T-cell expansion in target organs on day 7 or 14 (Figure 4B; supplemental Figure $6 \mathrm{~B}$ ) nor with an elevation in serum levels of inflammatory cytokines, such as IFN- $\gamma$, TNF- $\alpha$, IL-6, and IL-17A on day 7 (Figure 4C-D; supplemental Figure 6C-F). Nonetheless, consistent with survival data, the GVHD-specific histopathological score was higher only in the Gl tract of allogeneic XIAP ${ }^{-1-}$ animals on day 7 when compared with allogenic B6-WT animals (Figure 4E), but the scores of the other organs were similar (data not shown).

Similarly, enhanced GVHD mortality and clinical severity were observed in allogeneic clAP1 ${ }^{-1-}$ animals when compared with WT animals after BALB/c-into-B6 BMT ( $P=.02$; Figure 4F; supplemental Figure 6G). These data indicate that the absence of IAPs in hosts exacerbates GVHD and that use of the SMAC mimetic 


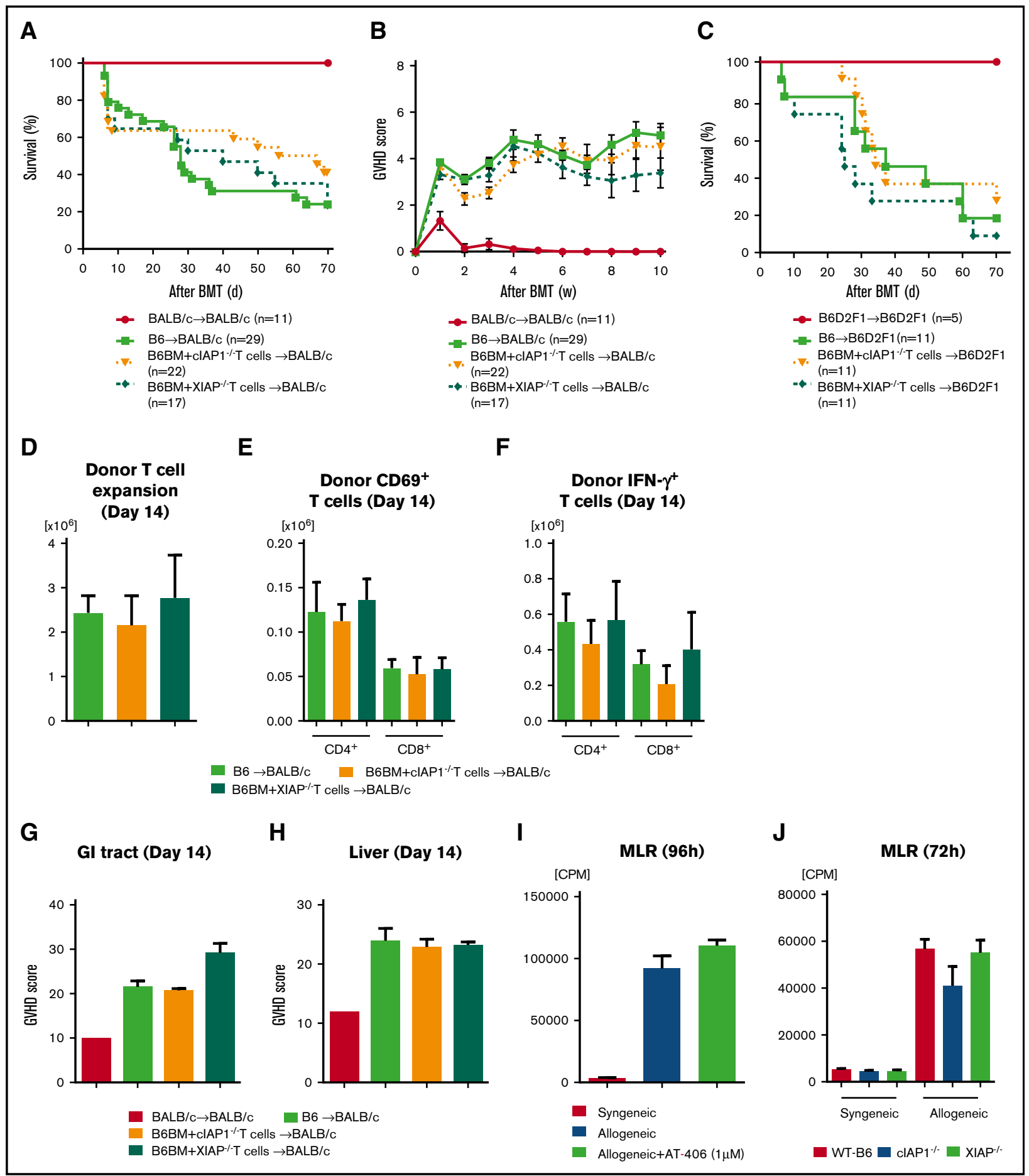

Figure 3. IAPs are not required in donor T cells to modulate GVH responses. (A-B) BALB/c animals received 8.5 Gy on day -1 and received transplants of $0.5 \times 10^{6}$ CD90. $2^{+}$splenic T cells from either syngeneic BALB/c or allogeneic MHC-mismatched B6-WT, B6-cIAP1 ${ }^{-1-}$, or B6-XIAP ${ }^{-1-}$ animals along with $5 \times 10^{6} \mathrm{TCD}^{\mathrm{B}} \mathrm{BM}$ cells from either syngeneic BALB/c or allogeneic B6 donors. Survival (A) and GVHD clinical score (B) ( $n=11-29$ per group). Pooled data from 4 independent experiments are shown. (C) B6D2F1-recipient animals received 11 Gy on day -1 and received transplants of $3 \times 10^{6} \mathrm{CD} 90.2^{+}$splenic T cells from either syngeneic B6D2F1 or haploidentical MHCmismatched B6-WT, B6-clAP1 ${ }^{-1-}$, or B6-XIAP ${ }^{-1-}$ animals along with $5 \times 10^{6} \mathrm{TCD}-\mathrm{BM}$ cells from either syngeneic B6D2F1 or allogenic B6 donors. Survival $(\mathrm{n}=5-11$ per group). Pooled data from 2 independent experiments are shown. (D-F) Expansion of donor T cells $\left(H-2 k^{b+} \mathrm{CD}^{+} \mathrm{CD} 8^{+}\right)(\mathrm{D}), \mathrm{CD} 69^{+} \mathrm{T}$ cells $(\mathrm{E})$, and IFN- $\gamma-\mathrm{producing} T$ cells $(\mathrm{F})$ in the spleen on day 14 after allo-BMT ( $n=3-4$ per group, pooled from 2 experiments). The bar shows the mean \pm SEM. (G-H) The histopathological GVHD score in the Gl tract (small and large intestines) $(\mathrm{G})$ and liver $(\mathrm{H})$ on day 14 after allo-BMT ( $\mathrm{n}=3-4$ per group, pooled from 2 experiments). The bar shows the mean \pm SEM. (I) In vitro MLR. Isolated splenic CD90.2 ${ }^{+}$T cells from either BALB/c or B6-WT animals were cultured with BMDCs derived from animals in the presence or absence of AT-406 ( $\left.1 \mu \mathrm{M}\right)$ for 96 hours and analyzed for proliferation after ${ }^{3} \mathrm{H}$-thymidine incorporation during the last 16 hours of incubation. A representative figure from 3 independent experiments is 
AT-406 may have similar adverse effects that are intrinsic to the host. They further suggest that XIAP and cIAP1 do not compensate for the absence of each other and that they have distinct effects on GVHD mortality.

\section{IAPs in host hematopoietic-derived APCs are dispensable for exacerbation of GVHD}

Host hematopoietic-derived APCs are central for initiating allogeneic reactive T-cell responses, ${ }^{28,29}$ and because expression of IAPs in the host is important for increasing GVHD severity, we next reasoned that IAP expression in host hematopoietic cells might be the critical cellular compartment mediating IAP-dependent severity in the recipients. Therefore, to evaluate the impact of IAP expression in hematopoietic APCs, we next explored in vitro the role of IAPs in DCs, the most potent APCs. We determined the expression of costimulatory molecules on splenic DCs from naïve B6-WT, $\mathrm{clAP}^{-/-}$, and $\mathrm{XIAP}^{-1-}$ animals to determine their phenotypes at homeostasis. Although the numbers of $\mathrm{CD}_{6}{ }^{+} \mathrm{CD} 11 \mathrm{c}^{+}$and class $\mathrm{II}^{+} \mathrm{CD} 11 \mathrm{c}^{+}$cells in $\mathrm{ClAP} 1^{-1-}$ animals were significantly higher than those in B6-WT animals, the absolute numbers of $\mathrm{CD} 11 \mathrm{c}^{+}, \mathrm{CD} 80^{+} \mathrm{CD} 11 \mathrm{c}^{+}, \mathrm{PDL}-1^{+}$ $\mathrm{CD} 11 \mathrm{c}^{+}$, and $\mathrm{CD}_{40} \mathrm{CD}^{+} 11 \mathrm{c}^{+}$cells were equivalent among these animals (supplemental Figure $7 \mathrm{~A}-\mathrm{F}$ ). BMDCs from $\mathrm{clAP} 1^{-1-}$ or $\mathrm{XIAP}^{-1-}$ animals showed a similar allogeneic T-cell stimulation capacity in an MLR when compared with B6-WT (Figure 5A). To further confirm whether AT-406 alters the allogeneic T-cell stimulation capacity of DCs, we pretreated B6-WT DCs with AT-406 before using them as stimulators in an MLR. We found that allogeneic T-cell stimulation was equivalent in both groups (Figure 5B). We next examined whether AT-406 altered the innate immune responses of DCs, such as TLR4-mediated responses after stimulation with lipopolysaccharide, but found similar responses in untreated and AT-406-treated DCs, as determined by their expression of costimulatory molecules as wells as secretion of TNF- $\alpha$ and IL- 6 (Figure 5C-E). Because cIAP1 and XIAP are recognized as regulators of nucleotide-binding oligomerization domain-containing protein (NOD)-1- and NOD-2-mediated innate immune responses, ${ }^{44,47}$ we also tested the responses to other pathogen-associated molecular patterns utilizing peptidoglycan and Pam3CSK4 as well as damage-associated molecular patterns utilizing high-mobility group protein 1 (HMGB-1) in DCs in vitro. Again, AT-406-treated DCs showed no alteration in their response to these various stimuli (supplemental Figure 7G-I).

To determine if the lack of in vitro differences was also observed in vivo in the context of GVHD, we next explored whether XIAP or cIAP1 expression in host hematopoietic-derived cells was critical for GVHD; we generated BM chimeras such that only the radiosensitive host hematopoietic cells either expressed or lacked IAPs. B6Ly5.2 animals were lethally irradiated with 11 Gy and infused with $5 \times 10^{6} \mathrm{BM}$ cells and $5 \times 10^{6}$ splenocytes from syngeneic B6-WT, B6-clAP1 ${ }^{-1-}$, or

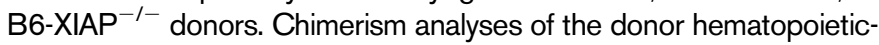
derived cells showed complete donor types (>95\%) 3 months after the first transplantation. The B6 $\rightarrow$ B6Ly5.2, clAP1 ${ }^{-/-} \rightarrow$ B6Ly5.2, and $\mathrm{XIAP}^{-1-} \rightarrow \mathrm{B} 6 \mathrm{Ly} 5.2$ animals were then used as recipients in a second allo-BMT 3 to 4 months after the primary BMT. In the second transplantation, all chimera animals received 9 Gy and received transplants of $3.0 \times 10^{6} \mathrm{CD}^{+}{ }^{+} \mathrm{T}$ cells along with $5 \times$ $10^{6} \mathrm{BM}$ cells from either syngeneic B6 or MHC-mismatched allogeneic BALB/c donors. All chimeras that received syngeneic $T$ cells and BM cells survived the duration of the observation period, with no signs of GVHD. In contrast, the allogeneic B6 $\rightarrow$ B6Ly5.2, $\mathrm{ClAP}^{-/-} \rightarrow \mathrm{B} 6 \mathrm{Ly} 5.2$, and $\mathrm{XIAP}^{-l-} \rightarrow \mathrm{B} 6 \mathrm{Ly} 5.2$ animals showed similar GVHD mortality and severity (Figure 5F-G). These results suggest that the exacerbation of GVHD in the absence of IAPs in the host or after AT-406 treatment is independent of IAPs in host hematopoietic-derived APCs.

\section{IAP expression in host nonhematopoietic cells plays an important role in GVHD}

Because host hematopoietic cell expression of IAPs was not essential to GVHD severity, we next determined whether their expression by nonhematopoietic cells in the host was critical for modulation of GVHD severity. ${ }^{41,54}$ Therefore, we hypothesized that IAP deficiency in nonhematopoietic GVHD target tissues exacerbates GVHD. To this end, we made the reverse chimeras, namely, B6Ly5.2 $\rightarrow$ B6, B6Ly5.2 $\rightarrow \mathrm{XIAP}^{-1-}$, and B6Ly5.2 $\rightarrow \mathrm{ClAP}^{-1-}$, where IAPs were absent only in the nonhematopoietic host cells. These chimeras received 9 Gy and received transplants of $3.0 \times 10^{6}$ ${\mathrm{CD} 90^{+}}^{\mathrm{T}}$ cells along with $5 \times 10^{6} \mathrm{BM}$ cells from either syngeneic B6 or MHC-mismatched allogeneic BALB/c donors. The allogeneic B6Ly5.2 $\rightarrow \mathrm{XIAP}^{-1-}$ animals lacking IAPs in nonhematopoietic tissues developed more severe GVHD and demonstrated significantly worse survival compared with B6Ly5.2 $\rightarrow \mathrm{B} 6$ recipients $(P<.0006$; Figure $6 \mathrm{~A})$. Similarly, the allogeneic B6Ly5.2 $\rightarrow \mathrm{ClAP}^{-1-}$ animals also showed significantly worse survival compared with B6Ly5.2 $\rightarrow$ B6 recipients $(P<.01$; Figure $6 \mathrm{~B})$. These data demonstrate mutually exclusive roles of XIAP and cIAP1 expression in contributing toward GVHD. Collectively, they demonstrate that IAP expression in host nonhematopoietic target tissues plays an important role in regulating GVHD severity.

\section{IAP expression alters apoptosis of GI epithelial cells and mitigates GVHD}

GVHD is characterized by target-cell apoptosis. ${ }^{25}$ Because IAPs regulate apoptosis ${ }^{1-3}$ and their role in nonhematopoietic target cells is critical for GI GVHD severity, ${ }^{25}$ we next tested the effect of IAPs on expression of anti- or proapoptotic proteins in $\mathrm{CD}_{2} 26^{+} \mathrm{IECs}$, which are critical for maintaining mucosal integrity in the gut after allo-BMT. ${ }^{55,56}$ We first confirmed whether allogeneic $\mathrm{XIAP}^{-1-}$ animals showed increased apoptosis in the Gl tract. We performed TUNEL staining in the intestine on day 7 after allo-BMT. Consistent with GVHD severity, allogeneic XIAP ${ }^{-1-}$ animals showed increased numbers of IECs stained with TUNEL compared with allogeneic WT animals (Figure 7A). To determine the potential mechanisms for enhanced apoptosis in target tissue, we next tested the expression of antiapoptotic (B-cell lymphoma-2 [BCL-2]) and proapoptotic (BCL-2-like protein 11 [BIM] and BCL-2-associated $X$ protein [BAX]) protein expression in the CD326 ${ }^{+}$IECs from B6-WT and $\mathrm{XIAP}^{-/-}$animals harvested on day 7 after allo-BMT. Both allogeneic

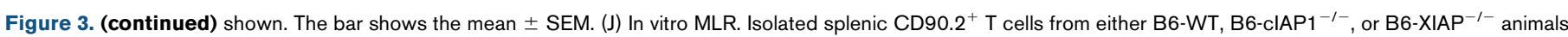

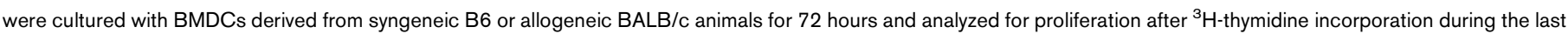
16 hours of incubation. The bar shows the mean \pm SEM. CPM, counts per minute. 


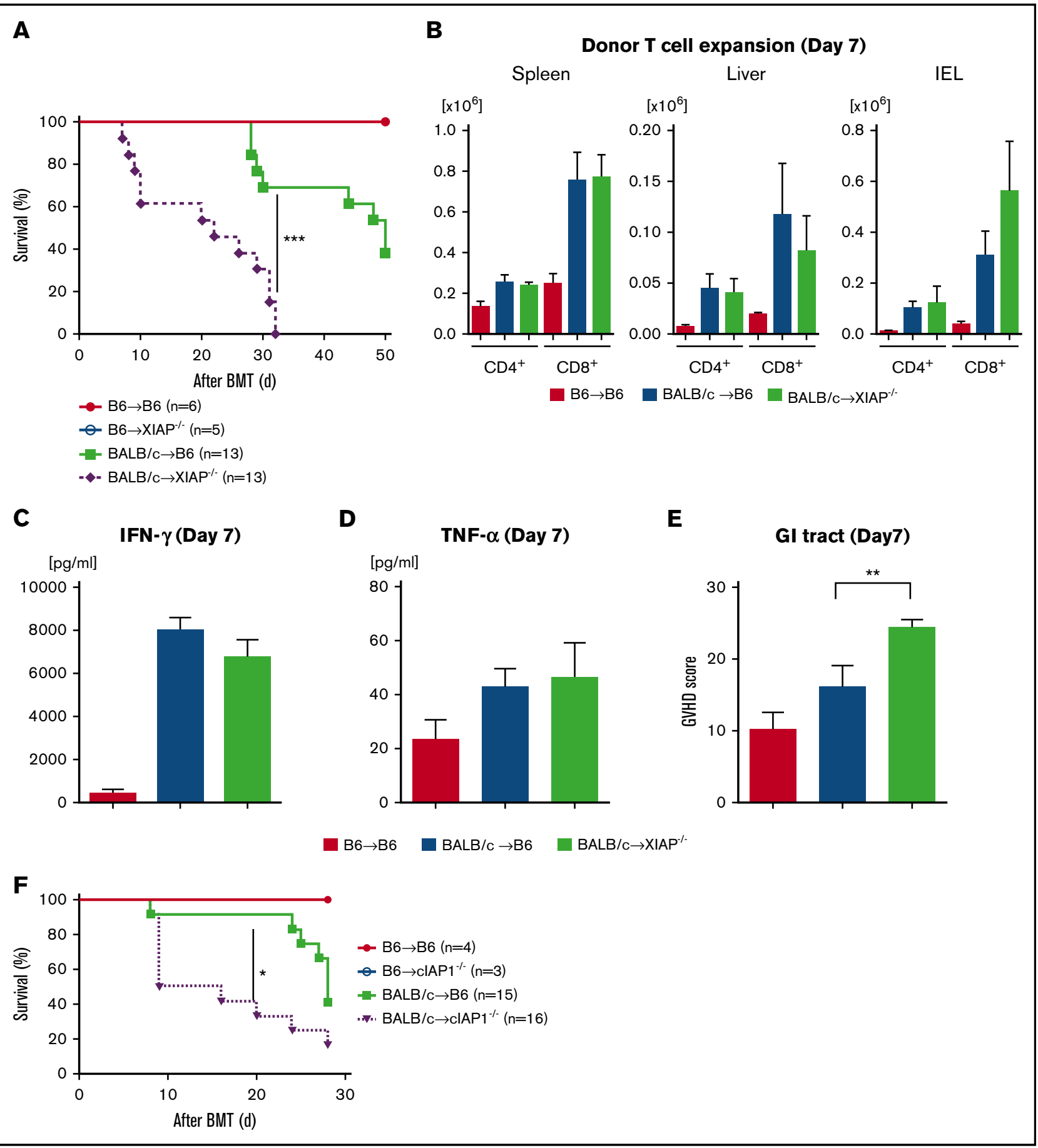

Figure 4. Absence of IAPs in host exacerbates GVHD in allo-BMT. B6-WT and B6-XIAP ${ }^{-1-}$ animals received 10 Gy on day -1 and received transplants of $3 \times 10^{6}$ CD90.2 ${ }^{+}$splenic T cells along with $5 \times 10^{6}$ TCD-BM cells from either syngeneic B6 or allogeneic MHC-mismatched BALB/c donors. (A) Survival ( $n=5-13$ per group). Pooled data from 3 independent experiments are shown. ${ }^{* *} P<.001$, when allogeneic WT control and allogeneic XIAP ${ }^{-1-}$ animals are compared. (B) Donor T-cell (H-2k ${ }^{\mathrm{d}+}$ $\mathrm{CD}^{+}$or $\mathrm{H}-2 \mathrm{k}^{\mathrm{d}+} \mathrm{CD}^{+}$) expansion in spleen, liver, and intraepithelial cells (IECs) on day 7 after allo-BMT ( $\mathrm{n}=4-6$ per group, pooled from 2 experiments). The bar shows the mean \pm SEM. (C-D) Serum levels of IFN- $\gamma(C)$ and TNF- $\alpha$ (D) on day 7 after allo-BMT ( $n=4-6$ per group, pooled from 2 experiments). ${ }^{*} P<.05$. The bar shows the mean \pm SEM. (E) The histopathological GVHD score in Gl tract (small and large intestines) on day 7 after allo-BMT ( $n=4-6$ per group, pooled from 2 experiments). ${ }^{\star \star} P<.01$. The bar shows the mean \pm SEM. (F) Survival. B6-WT and B6-clAP1 ${ }^{-1-}$ animals received 10 Gy on day -1 and received transplants of $3 \times 10^{6} \mathrm{CD} 90.2^{+}$ splenic T cells along with $5 \times 10^{6}$ TCD-BM cells from either syngeneic B6 or allogeneic MHC-mismatched BALB/c donors ( $n=3-16$ per group). Pooled data from 3 independent experiments are shown. ${ }^{*} P<.05$, when allogeneic WT control and allogeneic clAP1 ${ }^{-1-}$ animals are compared. 


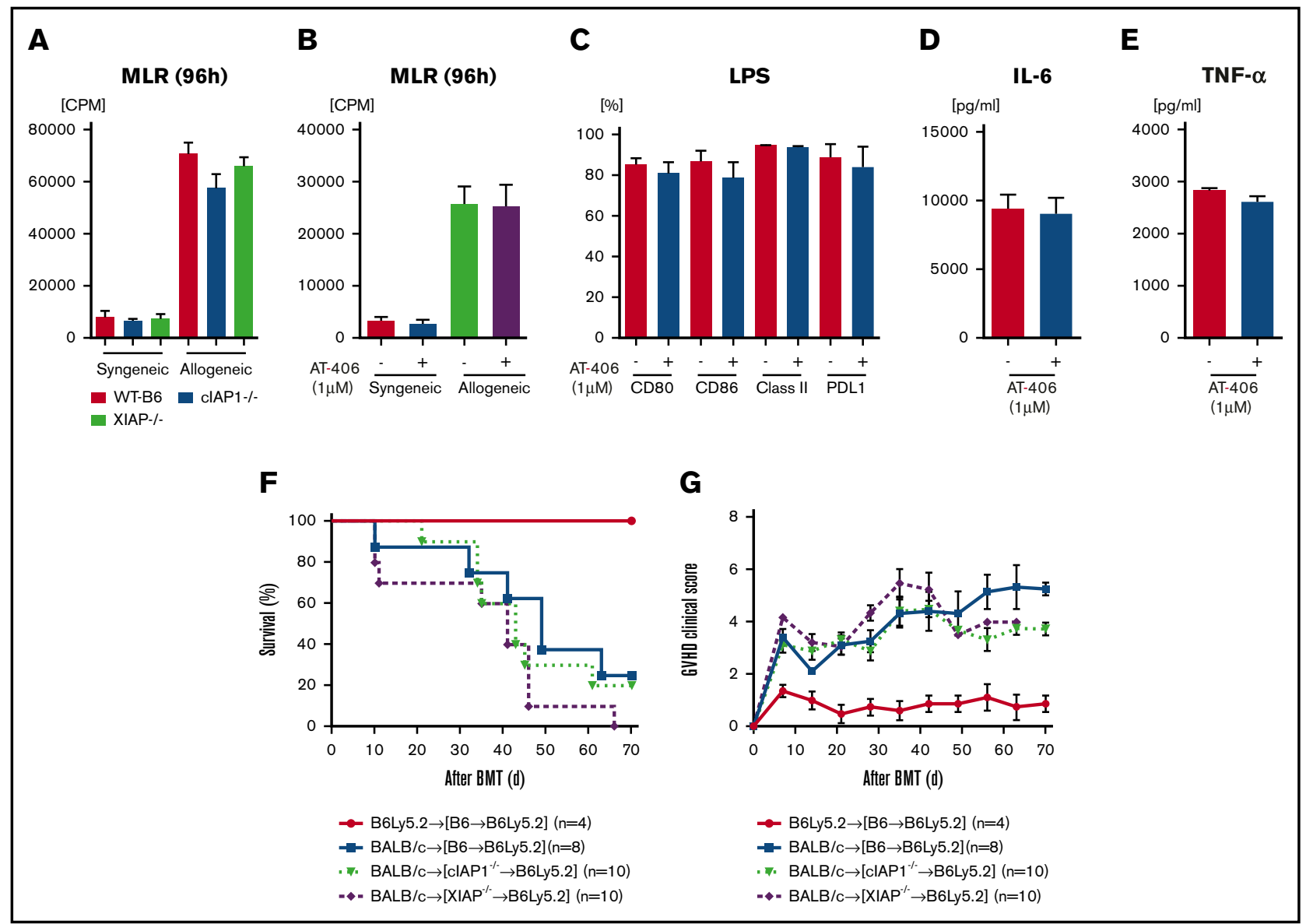

Figure 5. The role of IAPs in host hematopoietic-derived APCs is dispensable for GVHD. (A-B) In vitro MLR. Isolated splenic CD90.2 ${ }^{+}$T cells from either syngeneic B6 or allogeneic BALB/c animals were cultured with BMDCs derived from B6-WT, B6-cIAP1 ${ }^{-1-}$, or B6-XIAP ${ }^{-1-}$ animals for 96 hours (A) or with AT406-pretreated (1 $\mu \mathrm{M}$; 6 hours) BMDCs derived from B6-WT for 96 hours (B) and analyzed for proliferation after ${ }^{3} \mathrm{H}$-thymidine incorporation during the last 16 hours of incubation. Representative data of 3 independent experiments are shown. The bar shows the mean \pm SEM. (C-E) Both nontreated and AT406-pretreated (1 $\mu M)$ BMDCs were harvested and stimulated through TLR4 with lipopolysaccharide (LPS; $500 \mathrm{ng} / \mathrm{ml}$ ) for 16 hours. (C) Bar graphs depicting the percentages of CD80, CD86, I-A (MHC class II), and B7H1 (PD-L1) expression on CD11 $\mathrm{c}^{+}$DCs are shown. The supernatants were analyzed for IL-6 (D) and TNF- $\alpha$ (E) by ELISA. The data are representative of 3 independent experiments and show the means \pm SEMs. (F-G) To make BM chimeras, B6Ly5.2 animals were lethally irradiated with 11 Gy and infused with $5 \times 10^{6}$ BM cells and $5 \times 10^{6}$ splenocytes from syngeneic B6-WT, B6-clAP $1^{-1-}$, or B6-XIAP ${ }^{-1-}$ donors. Three to 4 months later, B6 $\rightarrow$ B6Ly5.2, clAP $1^{-1-} \rightarrow B 6$ Ly5.2, and XIAP ${ }^{-1-} \rightarrow B 6$ Ly5.2 animals were irradiated with 9 Gy and received $3 \times 10^{6} \mathrm{CD}^{+} \mathrm{T}$ cells along with $5 \times 10^{6} \mathrm{TCD}-\mathrm{BM}$ cells from either syngeneic B6 or allogeneic MHC-mismatched BALB/c donors. Survival (F) and clinical GVHD score (G) $(n=4-10$ per group). Pooled data from 2 independent experiments are shown.

$\mathrm{XIAP}^{-1-}$ and $\mathrm{ClAP}^{-1-}$ animals showed significantly reduced expression of antiapoptotic protein BCL-2 but equivalent expression of proapoptotic proteins (Figure 7B-D). In addition, the expression ratio of $\mathrm{BIM}$ or $\mathrm{BAX}$ to $\mathrm{BCL}-2$ in allogeneic $\mathrm{XIAP}^{-1-}$ animals was significantly increased (Figure 7E-F). These data suggest that enhanced apoptosis in the target tissues in the absence of IAPs contributes to greater GVHD severity.

Because apoptosis and autophagy coordinate to regulate cell survival and maintain homeostasis of the gut mucosa, ${ }^{57,58}$ we also examined whether IAP deficiency affected autophagy. We did not find any differences in the LC3 I to II conversion rate in the epithelial cells of the small intestine between B6-WT and XIAP ${ }^{-1-}$ animals on day 7 or 14 after allo-BMT. However, there was a significant decrease in the expression of LC3 in both small and large intestines of allogeneic $\mathrm{XIAP}^{-1-}$ animals at day 7 , indicating decreased autophagy (Figure 7G; supplemental Figure 8A). These data suggest that the enhanced apoptosis in both $\mathrm{XIAP}^{-1-}$ and cIAP $1^{-1-}$ animals and the reduced autophagy in the target tissues in the absence of XIAP may be potential mechanisms of enhanced GI GVHD. By contrast, allogeneic $\mathrm{ClAP}^{-1-}$ but not $\mathrm{XIAP}^{-1-}$ animals showed reduced level of Ras homolog gene family member A $(\rho-A)$ expression, which is known to control many cellular functions, ${ }^{59-61}$ cellular development, ${ }^{62}$ and gut homeostasis ${ }^{63}$ and is regulated by IAPs, in the small intestine at day 7 after allo-BMT (Figure $7 \mathrm{H}$ ). These data indicate that the absence of IAPs likely exacerbates GVHD damage by multiple, distinct cellular mechanisms.

\section{Discussion}

Our study demonstrates a novel role of IAPs in the regulation of GVHD and suggests that the effects of XIAP and cIAP1 expression and SMAC mimetic treatment after BMT are independent of effects 


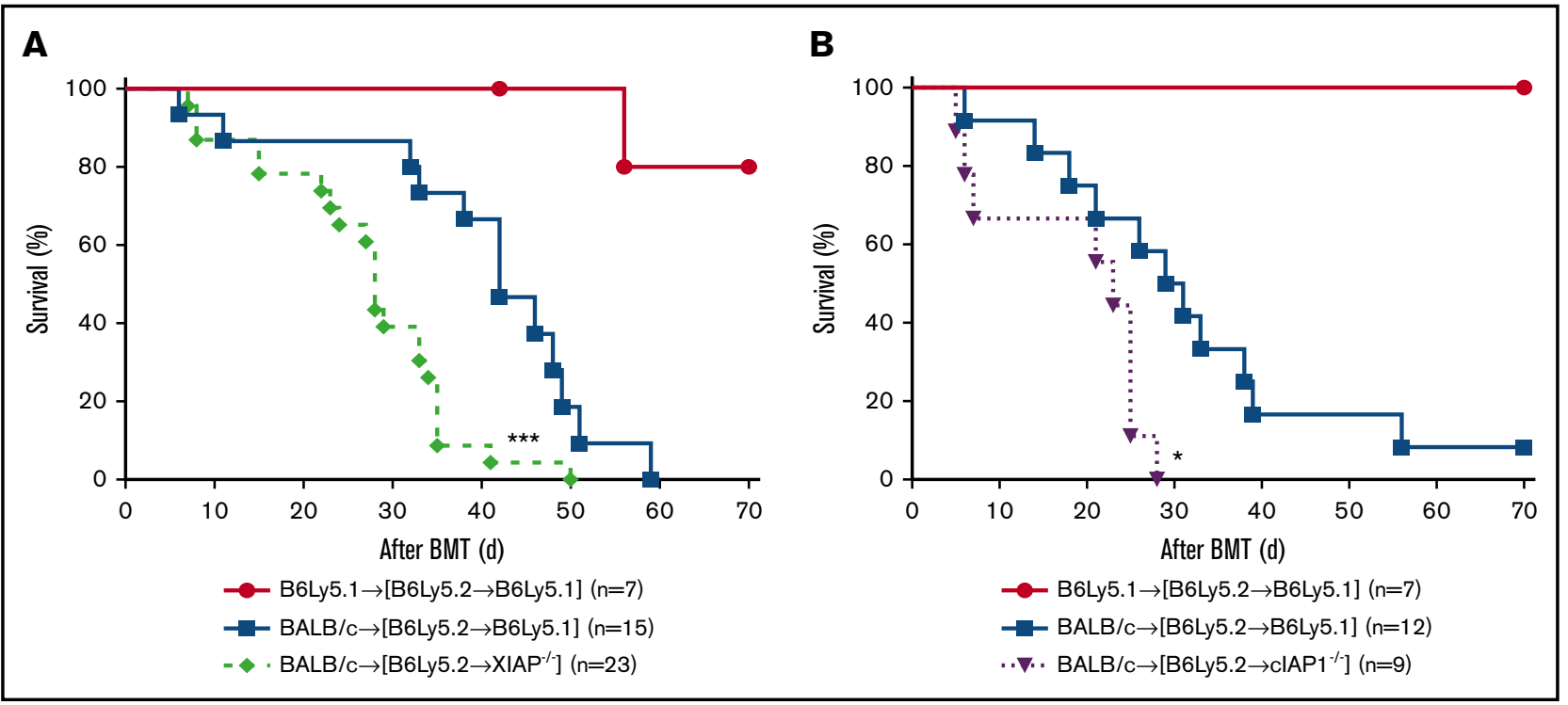

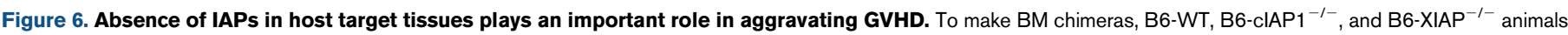
were lethally irradiated with 10 Gy and infused with $5 \times 10^{6} \mathrm{BM}$ cells and $5 \times 10^{6}$ splenocytes from syngeneic B6Ly5.2 donors. Three to 4 months later, B6 Ly5.2 $\rightarrow$ B6,

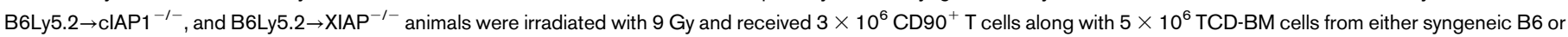

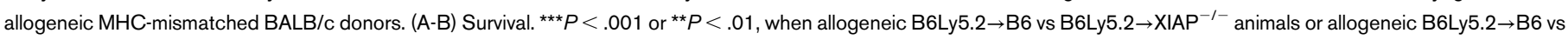
B6Ly5.2 $\rightarrow$ ClAP $^{-1-}$ animals were compared ( $n=9-27$ per group, pooled from 3 to 4 independent experiments). The bar shows the mean \pm SEM.

on donor $\mathrm{T}$ cells and host hematopoietic cells. Our data suggest that IAP expression in host nonhematopoietic target cells is important for regulation of GI GVHD damage.

The current understanding of the role of IAP regulation of innate immune responses seems to be dependent on the context. For example, IAPs have been suggested to regulate innate responses through the pattern recognition receptors ${ }^{24,44,47,64}$ by inhibiting cell-death signaling, ${ }^{16,17,44}$ controlling MAPK and NF- $\kappa B$ signaling pathways, ${ }^{45,65}$ and modifying inflammasomes or in the context of candida infections. ${ }^{20,66}$ In contrast, loss of cIAP or XIAP in the myeloid lineage caused overproduction of many inflammatory cytokines and severe sterile inflammation. ${ }^{21} \mathrm{We}$, however, found that the absence of IAPs in hematopoietic-derived APCs was not associated with increased GVHD severity or mortality. Rather, the absence of IAPs in host nonhematopoietic target tissues exacerbated GVHD in second BMT animals utilizing BM chimeras. Our data are consistent with and extend those in a recent report showing that cIAP1 protects TNF- $\alpha$-mediated destruction of IECs in a colitis model in part. ${ }^{67}$ We found that both XIAP and cIAP1 reduced GI GVHD. A remarkable observation of this study is that neither the absence of IAPs nor treatment with the SMAC mimetic AT-406 exacerbated conditioning-related Gl damage, as demonstrated by the absence of increased damage in syngeneic recipients (Figure $1 \mathrm{H}$; supplemental Figure 5C-F). Interestingly, IAP expression in IECs was temporally reduced at 24 hours after irradiation but spontaneously recovered at 48 hours (supplemental Figure 5A). This quick alteration may have an indispensable role in the cell-intrinsic self-tissue repair mechanism to maintain gut homeostasis after injury such as radiation toxicity. Therefore, our observations suggest that IAPs protect tissue damage in IECs only in the allogeneic immunity context. The reasons for this remain unknown. Whether IAPs mitigate damage mediated by donor $\mathrm{T}$ cells and are dispensable for nonspecific sterile inflammation or whether they also protect tissue damage from non-TBI conditioning will need to be further studied. In addition, whether IAPs regulate the gut microbiome, which is linked with gut GVHD, ${ }^{68}$ will need to further investigated.

Consistent with our observations, SMAC mimetics induce increased enterocyte shedding and loss of barrier function in piglet ileal mucosa after oral infection with Cryptosporidium parvum. ${ }^{69}$ Furthermore, a clinical study demonstrated that some patients with advanced solid tumors who received LCL16, which induces the degradation of clAP1, experienced grade 3 to 4 cytokine release syndrome. ${ }^{9}$ Altogether, these data suggest that inflammatory responses after the inhibition of IAPs may differ and depend on the context of inflammation and the target tissues.

Our data demonstrate that XIAP, cIAP1, or SMAC inhibition do not significantly alter T-cell responses to an allogeneic stimulus, either in vitro or in vivo. The differential effect on nonspecific antibodymediated in vitro stimulation from an allogeneic stimulus may be a consequence of the strength of stimulation and the absence of physiological engagement of the full panoply of costimulatory and coinhibitory receptors on an APC in the former context. IAPs are closely linked to inflammasome activation, as shown by studies utilizing $\mathrm{XIAP}^{-1-}$ or XIAP ${ }^{-1-} \mathrm{CIAP}^{-1-} \mathrm{CIAP}^{\text {LysMcre/LysMcre }}$ animals as well as SMAC mimetics. ${ }^{22,64}$ Inflammasome activation, such as NLRP3 in APCs or myeloid-derived suppressor cells, are involved in the development and aggravation of GVHD. ${ }^{70-72}$ However, we found that the serum levels of IL-1 $\beta$ and IL-18 in $\mathrm{XIAP}^{-1-}$ or $\mathrm{ClAP} 1^{-1-}$ animals were equivalent to those in WT animals after allo-BMT (data not shown). Thus, the contribution of IAPs to inflammasome activation is unlikely to be a critical component for its role in mitigating GVHD severity, but this would need to be formally tested.

Our observations suggest that the role of IAPs in gut GVHD is limited to nonhematopoietic target tissues, such as IECs. With regard to the function of IAPs in tissue homeostasis, increased IAP 


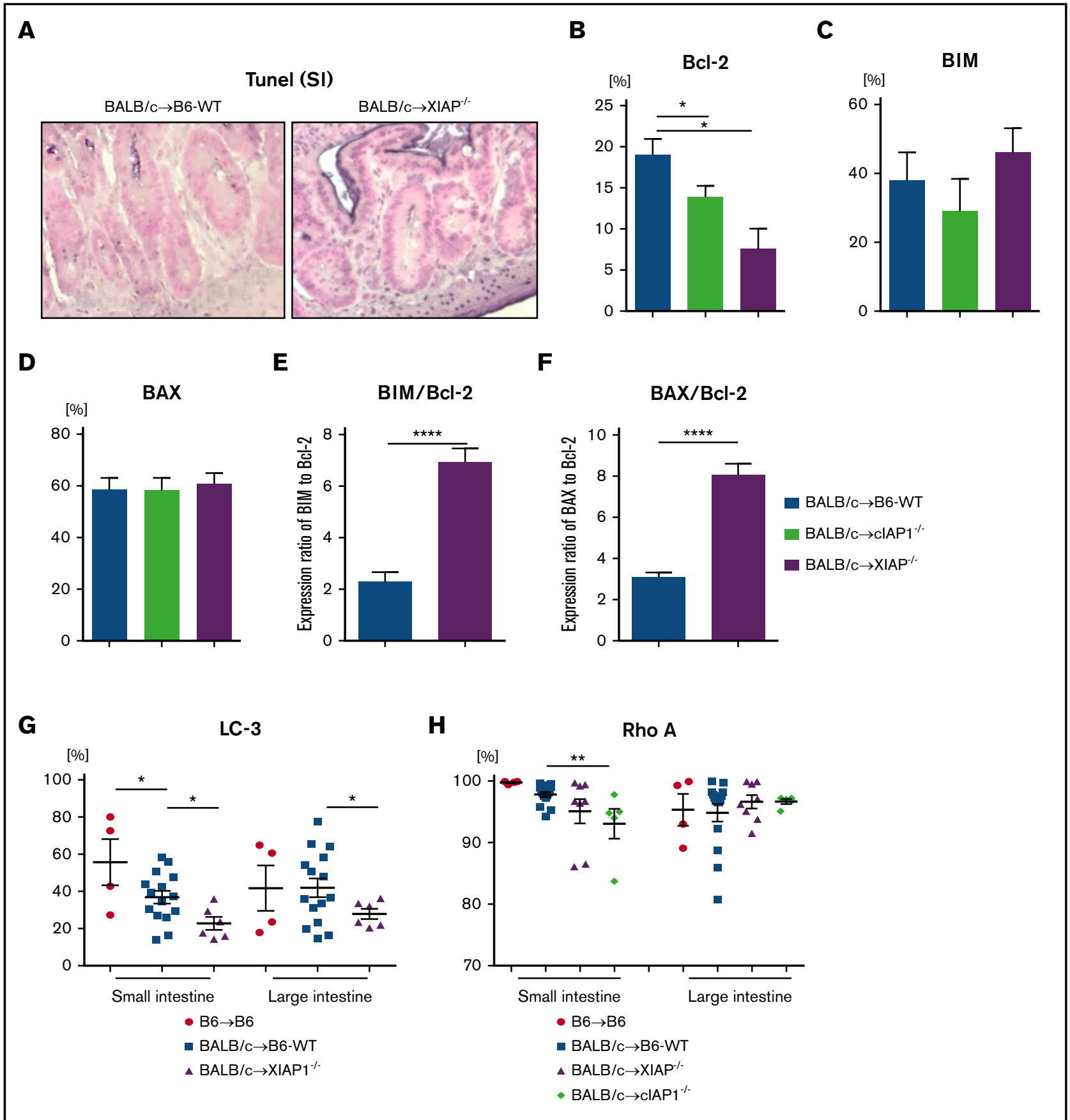

Figure 7. IAPs on host target tissues coordinately regulate gut homeostasis by distinct mechanisms in GVHD. B6-WT and B6-XIAP ${ }^{-1-}$ or clAP $1^{-/-}$animals received 10 Gy on day -1 and received transplants of $3 \times 10^{6} \mathrm{CD} 90.2^{+}$splenic T cells along with $5 \times 10^{6} \mathrm{TCD}-\mathrm{BM}$ cells from either syngeneic B6 or allogeneic MHC-mismatched BALB/c donors. TUNEL staining and anti- or proapoptotic protein expression in intestinal epithelial cells were evaluated on day 7 after allo-BMT. (A) The representative figures of TUNEL staining of small intestine on day 7 after allo-BMT are shown. Original magnification $\times 40$; TUNEL staining (nuclei purple) with a counterstain of Nuclear Fast Red (nuclei pink). (B-F) The expression of anti- or proapoptotic proteins in $\mathrm{CD}_{2} 26^{+}$intestinal epithelial cells on day 7 after allo-BMT: BCL-2 (B), BIM (C), BAX (D), and the ratios of BIM/BCL-2 (E) and BAX/BCL-2 (F). (G) LC3 expression in $\mathrm{CD}_{2} 26^{+}$intestinal epithelial cells from animals receiving transplants on day 7 after BMT was analyzed by $F A C S$ ( $n=4-15$, pooled from 3 independent experiments). ${ }^{\star} P<.05$, ${ }^{* *} P<.01,{ }^{* \star \star *} P<.0001$. The data are the means \pm SEMs. $(\mathrm{H}) \rho-\mathrm{A}$ expression in $\mathrm{CD} 326^{+}$intestinal epithelial cells from animals receiving transplants on day 7 after BMT was analyzed by FACS $\left(n=4-15\right.$, pooled from 3 independent experiments). ${ }^{* \star} P<.01$, when compared between allogeneic B6-WT and clAP ${ }^{-1-}$ animals. The data are the means \pm SEMs.

expression in IECs after IL-11 treatment seems to promote wound healing and regeneration in IBD, and the disruption of IAP signaling impairs regenerative process in the intestine and worsens IBD. ${ }^{73} \mathrm{In}$ addition, inhibition of IAPs with SMAC mimetics increased enterocyte shedding and loss of barrier function in piglet ileal mucosa after oral infection with Cryptosporidium parvum, a significant 
diarrhea-inducing pathogen. ${ }^{69}$ These data are in part consistent with our results and indicate that a delicate balance may exist in the function of IAPs. Our data might also explain clinical observations in XIAP patients. For example, these data are consistent with the clinical observation that patients with $\mathrm{X}$-linked lymphoproliferative disease 2 who have an XIAP-inactivating mutation develop severe intestinal inflammation. ${ }^{74}$ Furthermore, a recent clinical study demonstrated that the outcome of XIAP-deficient recipients who underwent allo-HCT after myeloablative conditioning was poor. ${ }^{75}$ XIAP-deficient patients show increased apoptosis of their lymphocytes after various stimulations and a decreased number of NK T cells. ${ }^{6}$ Up to $20 \%$ of patients with XIAP mutations develop IBD and systemic inflammation. ${ }^{74,76,77}$ Our data show how IAPs contribute to GI GVHD and, when taken in light of earlier observations in IBD and XIAP patients, point to the contribution of tissue tolerance in the maintenance of gut homeostasis in the context of allogeneic immunity. Interestingly, recent clinical observations suggests that XIAP or clAP1 polymorphisms are presumably associated with hereditary periodic fever syndromes ${ }^{78}$ and asthma susceptibility. ${ }^{79}$ Whether specific human polymorphisms of IAPs are involved in the severity of human host susceptibility to GI GVHD would certainly be of great interest, but would represent a risk factor rather than a biomarker. We found that antiapoptotic protein $\mathrm{BCL}-2$ was decreased in the IECs of $\mathrm{CIAP} 1^{-1-}$ and $\mathrm{XIAP}^{-1-}$ animals and was associated with a significant increase in the ratio of proapoptotic to antiapoptotic proteins. XIAP inhibits the mitochondrial apoptosis pathway by activating caspases 3,7 , and $9 .^{80}$ Therefore, inhibiting XIAP may increase this signaling and promote apoptosis of epithelial cells. We also found that IECs in XIAP ${ }^{-1-}$ animals showed low LC3 expression after allo-BMT. Because autophagy plays an important role in maintaining Gl homeostasis and its absence has a negative impact on gut inflammation, ${ }^{57,58,81,82}$ it may be a potential mechanism of increased gut damage in $\mathrm{XIAP}^{-1-}$ animals. How XIAP regulates autophagy in IECs will be great interest, and additional detailed studies will be required. To explore potential mechanisms of increased gut GVHD in IAP-deficient animals, we also tested IL-22, which is a critical regulator of gut homeostasis, ${ }^{83}$ and lgr5 expression, which is an intestinal stem-cell marker, deletion of which is involved in the severity of gut $\mathrm{GVHD}^{83,84}$; however, both IL-22 and lgr5 expression in IAP-deficient animals were comparable to those in WT animals (supplemental Figure 8B-C). Interestingly, $\mathrm{ClAP}^{-1-}$ animals showed reduced levels of $\rho$-A expression. IAPs directly regulate $\rho$ GTPases, which are known to control many cellular functions, ${ }^{59-61}$ cellular development, ${ }^{62}$ and gut homeostasis. $^{63}$ Recent studies have suggested that $\rho$-A inactivation ${ }^{63}$ and Ras-related C3 botulium toxin substrate (Rac1) activation ${ }^{85}$ are associated with $\mathrm{IBD}^{63,86}$ and that IAPs moderate these signaling pathways. ${ }^{87}$ Therefore, the $\rho$-A signaling pathway, in addition to increasing apoptosis, may be a potential mechanism of enhancing GVHD in clAP1 $^{-1-}$ animals. Because both autophagy and $\rho-\mathrm{A}$ signaling play important roles in maintaining Gl homeostasis and their absence has a negative impact on gut inflammation, ${ }^{63,88,89}$ enhancing autophagy or $\rho-A$ signaling might protect against $\mathrm{Gl}$ damage and ameliorate GVHD after allo-BMT. Although these will be explored in future studies, whether they are uniquely relevant for cIAP- or also important for XIAP-induced mechanisms remains unknown. A notable aspect of our data is that the significant impact of IAP expression was observed only with regard to the severity of GI GVHD, but not with skin or liver GVHD. The mechanisms for Gl-specific reduction of GVHD will be explored in future studies. However, these data point to the possibility that tissue-intrinsic mechanisms that protect them from immune-mediated damage might be distinct among various GVHD target organs. Collectively, these results suggest that the expression of IAPs in host target tissues might regulate a complex signaling network that protects the Gl tract from severe damage in settings of intense inflammatory injury, such as GVHD.

In conclusion, our data demonstrate a novel role for IAPs in the regulation of GVHD within target organs and independent of their role in donor $\mathrm{T}$ cells or host hematopoietic cells. Our data suggest that altering IAP-dependent target tissue sensitivity to apoptosis may represent a novel strategy to reduce GVHD severity.

\section{Acknowledgments}

This work was supported by grants from the National Institutes of Health, National Heart, Lung, and Blood Institute (HL090775 and HL128046) and National Cancer Institute (CA173878 and CA203542), an American Society of Blood and Marrow Transplantation New Investigator Award (T.T.), and a Dragon Bleu Foundation fellowship from Switzerland and Kurt and Senta Herrmann-Stiftung fellowship from Lichtenstein (C.R.).

\section{Authorship}

Contribution: T.T. designed and performed experiments, analyzed the data, and wrote the paper; C.R. performed experiments, analyzed the data, and wrote the paper; K.O.-W. performed experiments; C.Z. performed experiments; C.L. performed experiments and histopathological analysis; S.-R.J.W., Y.S., H.F., H.T., D.P., I.H., M.R., and S.B. performed experiments; C.S.D. contributed reagents and the XIAP/cIAP1-deficient animals and contributed intellectually; S.W. contributed intellectually and contributed the reagents and SMAC mimetic; and P.R. designed experiments, analyzed the data, and wrote the paper.

Conflict-of-interest disclosure: The authors declare no competing financial interests.

Correspondence: Pavan Reddy, Department of Internal Medicine, Division of Hematology and Oncology, Blood and Marrow Transplantation Program, University of Michigan Comprehensive Cancer Center, 3312 CCGC, 1500 E. Medical Center Dr, Ann Arbor, Ml 48105-1942; e-mail: reddypr@med.umich.edu.

\section{References}

1. Beug ST, Cheung HH, LaCasse EC, Korneluk RG. Modulation of immune signalling by inhibitors of apoptosis. Trends Immunol. 2012;33(11):535-545.

2. Pedersen J, LaCasse EC, Seidelin JB, Coskun M, Nielsen OH. Inhibitors of apoptosis (IAPs) regulate intestinal immunity and inflammatory bowel disease (IBD) inflammation. Trends Mol Med. 2014;20(11):652-665. 
3. Vandenabeele P, Bertrand MJ. The role of the IAP E3 ubiquitin ligases in regulating pattern-recognition receptor signalling. Nat Rev Immunol. 2012; 12(12):833-844.

4. Deveraux QL, Takahashi R, Salvesen GS, Reed JC. X-linked IAP is a direct inhibitor of cell-death proteases. Nature. 1997;388(6639):300-304.

5. Hayden MS, Ghosh S. Shared principles in NF-kappaB signaling. Cell. 2008;132(3):344-362.

6. Rigaud S, Fondanèche MC, Lambert N, et al. XIAP deficiency in humans causes an X-linked lymphoproliferative syndrome. Nature. 2006;444(7115): 110-114.

7. Marsh RA, Madden L, Kitchen BJ, et al. XIAP deficiency: a unique primary immunodeficiency best classified as X-linked familial hemophagocytic lymphohistiocytosis and not as X-linked lymphoproliferative disease. Blood. 2010;116(7):1079-1082.

8. Speckmann C, Ehl S. XIAP deficiency is a mendelian cause of late-onset IBD. Gut. 2014;63(6):1031-1032.

9. Infante JR, Dees EC, Olszanski AJ, et al. Phase I dose-escalation study of LCL161, an oral inhibitor of apoptosis proteins inhibitor, in patients with advanced solid tumors. J Clin Oncol. 2014;32(28):3103-3110.

10. Schimmer AD, Estey EH, Borthakur G, et al. Phase I/Il trial of AEG35156 X-linked inhibitor of apoptosis protein antisense oligonucleotide combined with idarubicin and cytarabine in patients with relapsed or primary refractory acute myeloid leukemia. J Clin Oncol. 2009;27(28):4741-4746.

11. Fulda S, Vucic D. Targeting IAP proteins for therapeutic intervention in cancer. Nat Rev Drug Discov. 2012;11(2):109-124.

12. Du C, Fang M, Li Y, Li L, Wang X. Smac, a mitochondrial protein that promotes cytochrome c-dependent caspase activation by eliminating IAP inhibition. Cell. 2000;102(1):33-42.

13. Yang Y, Fang S, Jensen JP, Weissman AM, Ashwell JD. Ubiquitin protein ligase activity of IAPs and their degradation in proteasomes in response to apoptotic stimuli. Science. 2000;288(5467):874-877.

14. Hay BA, Wassarman DA, Rubin GM. Drosophila homologs of baculovirus inhibitor of apoptosis proteins function to block cell death. Cell. 1995;83(7): 1253-1262.

15. Harlin H, Reffey SB, Duckett CS, Lindsten T, Thompson CB. Characterization of XIAP-deficient mice. Mol Cell Biol. 2001;21(10):3604-3608.

16. Varfolomeev E, Blankenship JW, Wayson SM, et al. IAP antagonists induce autoubiquitination of c-IAPs, NF-kappaB activation, and TNFalpha-dependent apoptosis. Cell. 2007;131(4):669-681.

17. Vince JE, Wong WW, Khan N, et al. IAP antagonists target clAP1 to induce TNFalpha-dependent apoptosis. Cell. 2007;131(4):682-693.

18. Bai L, Smith DC, Wang S. Small-molecule SMAC mimetics as new cancer therapeutics. Pharmacol Ther. 2014;144(1):82-95.

19. Gaither A, Porter D, Yao Y, et al. A Smac mimetic rescue screen reveals roles for inhibitor of apoptosis proteins in tumor necrosis factor-alpha signaling. Cancer Res. 2007;67(24):11493-11498.

20. Vince JE, Wong WW, Gentle I, et al. Inhibitor of apoptosis proteins limit RIP3 kinase-dependent interleukin-1 activation. Immunity. 2012;36(2):215-227.

21. Wong WW, Vince JE, Lalaoui N, et al. cIAPs and XIAP regulate myelopoiesis through cytokine production in an RIPK1-and RIPK3-dependent manner. Blood. 2014;123(16):2562-2572.

22. Yabal M, Müller N, Adler H, et al. XIAP restricts TNF- and RIP3-dependent cell death and inflammasome activation. Cell Reports. 2014;7(6):1796-1808.

23. Mayer BA, Rehberg M, Erhardt A, et al. Inhibitor of apoptosis proteins as novel targets in inflammatory processes. Arterioscler Thromb Vasc Biol. 2011; 31(10):2240-2250.

24. Tseng PH, Matsuzawa A, Zhang W, Mino T, Vignali DA, Karin M. Different modes of ubiquitination of the adaptor TRAF3 selectively activate the expression of type I interferons and proinflammatory cytokines. Nat Immunol. 2010;11(1):70-75.

25. Ferrara JL, Levine JE, Reddy P, Holler E. Graft-versus-host disease. Lancet. 2009;373(9674):1550-1561.

26. Akira S, Uematsu S, Takeuchi O. Pathogen recognition and innate immunity. Cell. 2006;124(4):783-801.

27. Liu Y, Chen GY, Zheng P. CD24-Siglec G/10 discriminates danger- from pathogen-associated molecular patterns. Trends Immunol. 2009;30(12): 557-561.

28. Shlomchik WD, Couzens MS, Tang CB, McNiff J, Robert ME, Liu J, et al. Prevention of graft versus host disease by inactivation of host antigen-presenting cells. Science. 1999;285(5426):412-415.

29. Teshima T, Ordemann R, Reddy P, Gagin S, Liu C, Cooke KR, et al. Acute graft-versus-host disease does not require alloantigen expression on host epithelium. Nat Med. 2002;8(6):575-581.

30. Cai Q, Sun H, Peng Y, et al. A potent and orally active antagonist (SM-406/AT-406) of multiple inhibitor of apoptosis proteins (IAPs) in clinical development for cancer treatment. J Med Chem. 2011;54(8):2714-2726.

31. Sun H, Lu J, Liu L, Yang CY, Wang S. Potent and selective small-molecule inhibitors of clAP1/2 proteins reveal that the binding of Smac mimetics to XIAP BIR3 is not required for their effective induction of cell death in tumor cells. ACS Chem Biol. 2014;9(4):994-1002.

32. Hurwitz HI, Smith DC, Pitot HC, et al. Safety, pharmacokinetics, and pharmacodynamic properties of oral DEBIO1143 (AT-406) in patients with advanced cancer: results of a first-in-man study. Cancer Chemother Pharmacol. 2015;75(4):851-859.

33. DiPersio JF, Erba HP, Larson RA, et al. Oral Debio1143 (AT406), an antagonist of inhibitor of apoptosis proteins, combined with daunorubicin and cytarabine in patients with poor-risk acute myeloid leukemia—results of a phase I dose-escalation study. Clin Lymphoma Myeloma Leuk. 2015;15(7): 443-449.

34. Reddy P, Maeda Y, Liu C, Krijanovski OI, Korngold R, Ferrara JL. A crucial role for antigen-presenting cells and alloantigen expression in graft-versusleukemia responses. Nat Med. 2005;11(11):1244-1249. 
35. Toubai T, Hou G, Mathewson N, et al. Siglec-G-CD24 axis controls the severity of graft-versus-host disease in mice. Blood. 2014;123(22):3512-3523.

36. Toubai T, Sun Y, Luker G, Liu J, Luker KE, Tawara I, et al. Host-derived CD8+ dendritic cells are required for induction of optimal graft-versus-tumor responses after experimental allogeneic bone marrow transplantation. Blood. 2013;121(20):4231-4241.

37. Toubai T, Sun Y, Tawara I, et al. Ikaros-Notch axis in host hematopoietic cells regulates experimental graft-versus-host disease. Blood. 2011;118(1): 192-204.

38. Reddy P, Sun Y, Toubai T, et al. Histone deacetylase inhibition modulates indoleamine 2,3-dioxygenase-dependent DC functions and regulates experimental graft-versus-host disease in mice. J Clin Invest. 2008;118(7):2562-2573.

39. Cooke KR, Hill GR, Crawford JM, et al. Tumor necrosis factor- alpha production to lipopolysaccharide stimulation by donor cells predicts the severity of experimental acute graft-versus-host disease. J Clin Invest. 1998;102(10):1882-1891.

40. Hill GR, Cooke KR, Teshima T, et al. Interleukin-11 promotes $T$ cell polarization and prevents acute graft-versus-host disease after allogeneic bone marrow transplantation. J Clin Invest. 1998;102(1):115-123.

41. Toubai T, Tawara I, Sun Y, Liu C, Nieves E, Evers R, et al. Induction of acute GVHD by sex-mismatched $\mathrm{H}$-Y antigens in the absence of functional radiosensitive host hematopoietic-derived antigen-presenting cells. Blood. 2012;119(16):3844-3853.

42. Zhang Y, Shlomchik WD, Joe G, et al. APCs in the liver and spleen recruit activated allogeneic CD8+ T cells to elicit hepatic graft-versus-host disease. $J$ Immunol. 2002;169(12):7111-7118.

43. Montufar-Solis D, Klein JR. An improved method for isolating intraepithelial lymphocytes (IELs) from the murine small intestine with consistently high purity. J Immunol Methods. 2006;308(1-2):251-254.

44. Bertrand MJ, Doiron K, Labbé K, Korneluk RG, Barker PA, Saleh M. Cellular inhibitors of apoptosis clAP1 and clAP2 are required for innate immunity signaling by the pattern recognition receptors NOD1 and NOD2. Immunity. 2009;30(6):789-801.

45. Mahoney DJ, Cheung HH, Mrad RL, et al. Both clAP1 and clAP2 regulate TNFalpha-mediated NF-kappaB activation. Proc Natl Acad Sci USA. 2008; 105(33):11778-11783.

46. Varfolomeev $\mathrm{E}$, Goncharov T, Maecker $\mathrm{H}$, et al. Cellular inhibitors of apoptosis are global regulators of NF-кB and MAPK activation by members of the TNF family of receptors. Sci Signal. 2012;5(216):ra22.

47. Krieg A, Correa RG, Garrison JB, et al. XIAP mediates NOD signaling via interaction with RIP2. Proc Natl Acad Sci USA. 2009;106(34):14524-14529.

48. Piguet PF, Grau GE, Allet B, Vassalli P. Tumor necrosis factor/cachectin is an effector of skin and gut lesions of the acute phase of graft-vs.-host disease. $J$ Exp Med. 1987;166(5):1280-1289.

49. Zhang T, Li Y, Zou P, et al. Physiologically based pharmacokinetic and pharmacodynamic modeling of an antagonist (SM-406/AT-406) of multiple inhibitor of apoptosis proteins (IAPs) in a mouse xenograft model of human breast cancer. Biopharm Drug Dispos. 2013;34(6):348-359.

50. Brunckhorst MK, Lerner D, Wang S, Yu Q. AT-406, an orally active antagonist of multiple inhibitor of apoptosis proteins, inhibits progression of human ovarian cancer. Cancer Biol Ther. 2012;13(9):804-811.

51. Korngold R, Sprent J. Lethal graft-versus-host disease after bone marrow transplantation across minor histocompatibility barriers in mice. Prevention by removing mature T cells from marrow. J Exp Med. 1978;148(6):1687-1698.

52. Gentle IE, Moelter I, Lechler N, et al. Inhibitors of apoptosis proteins (IAPs) are required for effective T-cell expansion/survival during antiviral immunity in mice. Blood. 2014;123(5):659-668.

53. Dougan M, Dougan S, Slisz J, et al. IAP inhibitors enhance co-stimulation to promote tumor immunity. J Exp Med. 2010;207(10):2195-2206.

54. Koyama M, Kuns RD, Olver SD, Raffelt NC, Wilson YA, Don AL, et al. Recipient nonhematopoietic antigen-presenting cells are sufficient to induce lethal acute graft-versus-host disease. Nat Med. 2012;18(1):135-142.

55. Hawkins CJ, Uren AG, Häcker G, Medcalf RL, Vaux DL. Inhibition of interleukin 1 beta-converting enzyme-mediated apoptosis of mammalian cells by baculovirus IAP. Proc Natl Acad Sci USA. 1996;93(24):13786-13790.

56. Uren AG, Pakusch M, Hawkins CJ, Puls KL, Vaux DL. Cloning and expression of apoptosis inhibitory protein homologs that function to inhibit apoptosis and/or bind tumor necrosis factor receptor-associated factors. Proc Natl Acad Sci USA. 1996;93(10):4974-4978.

57. Groulx JF, Khalfaoui T, Benoit YD, et al. Autophagy is active in normal colon mucosa. Autophagy. 2012;8(6):893-902.

58. Mukhopadhyay S, Panda PK, Sinha N, Das DN, Bhutia SK. Autophagy and apoptosis: where do they meet? Apoptosis. 2014;19(4):555-566.

59. Etienne-Manneville S, Hall A. Rho GTPases in cell biology. Nature. 2002;420(6916):629-635.

60. Geisbrecht ER, Montell DJ. A role for Drosophila IAP1-mediated caspase inhibition in Rac-dependent cell migration. Cell. 2004;118(1):111-125.

61. Oberoi-Khanuja TK, Murali A, Rajalingam K. IAPs on the move: role of inhibitors of apoptosis proteins in cell migration. Cell Death Dis. $2013 ; 4$ :e784.

62. Kenneth NS, Duckett CS. IAP proteins: regulators of cell migration and development. Curr Opin Cell Biol. 2012;24(6):871-875.

63. López-Posadas R, Becker C, Günther C, et al. Rho-A prenylation and signaling link epithelial homeostasis to intestinal inflammation. $J$ Clin Invest. 2016; $126(2): 611-626$.

64. Damgaard RB, Nachbur U, Yabal M, et al. The ubiquitin ligase XIAP recruits LUBAC for NOD2 signaling in inflammation and innate immunity. Mol Cell. 2012;46(6):746-758.

65. Moulin M, Anderton H, Voss AK, et al. IAPs limit activation of RIP kinases by TNF receptor 1 during development. EMBO J. $2012 ; 31(7): 1679-1691$.

66. Labbé K, Mclntire CR, Doiron K, Leblanc PM, Saleh M. Cellular inhibitors of apoptosis proteins clAP1 and clAP2 are required for efficient caspase-1 activation by the inflammasome. Immunity. 2011;35(6):897-907. 
67. Grabinger T, Bode KJ, Demgenski J, et al. Inhibitor of apoptosis protein-1 regulates tumor necrosis factor-mediated destruction of intestinal epithelial cells. Gastroenterology. 2017;152(4):867-879.

68. Jenq RR, Ubeda C, Taur Y, et al. Regulation of intestinal inflammation by microbiota following allogeneic bone marrow transplantation. J Exp Med. 2012; 209(5):903-911.

69. Foster DM, Stauffer SH, Stone MR, Gookin JL. Proteasome inhibition of pathologic shedding of enterocytes to defend barrier function requires X-linked inhibitor of apoptosis protein and nuclear factor kappaB. Gastroenterology. 2012;143(1):133-144.e4.

70. Jankovic D, Ganesan J, Bscheider M, et al. The Nlrp3 inflammasome regulates acute graft-versus-host disease. J Exp Med. 2013;210(10):1899-1910.

71. Chen S, Smith BA, lype J, et al. MicroRNA-155-deficient dendritic cells cause less severe GVHD through reduced migration and defective inflammasome activation. Blood. 2015;126(1):103-112.

72. Koehn BH, Apostolova P, Haverkamp JM, et al. GVHD-associated, inflammasome-mediated loss of function in adoptively transferred myeloid-derived suppressor cells. Blood. 2015;126(13):1621-1628.

73. Naugler KM, Baer KA, Ropeleski MJ. Interleukin-11 antagonizes Fas ligand-mediated apoptosis in IEC-18 intestinal epithelial crypt cells: role of MEK and Akt-dependent signaling. Am J Physiol Gastrointest Liver Physiol. 2008;294(3):G728-G737.

74. Zeissig Y, Petersen BS, Milutinovic S, et al. XIAP variants in male Crohn's disease. Gut. 2015;64(1):66-76.

75. Marsh RA, Rao K, Satwani $P$, et al. Allogeneic hematopoietic cell transplantation for XIAP deficiency: an international survey reveals poor outcomes. Blood. 2013;121(6):877-883.

76. Aguilar C, Latour S. X-linked inhibitor of apoptosis protein deficiency: more than an X-linked lymphoproliferative syndrome. J Clin Immunol. 2015;35(4): 331-338.

77. Pachlopnik Schmid J, Canioni D, Moshous D, et al. Clinical similarities and differences of patients with X-linked lymphoproliferative syndrome type 1 (XLP-1/SAP deficiency) versus type 2 (XLP-2/XIAP deficiency). Blood. 2011;117(5):1522-1529.

78. Ferretti M, Gattorno M, Chiocchetti A, et al. The $423 \mathrm{Q}$ polymorphism of the X-linked inhibitor of apoptosis gene influences monocyte function and is associated with periodic fever. Arthritis Rheum. 2009;60(11):3476-3484.

79. Roscioli E, Hamon R, Ruffin RE, et al. BIRC3 single nucleotide polymorphism associate with asthma susceptibility and the abundance of eosinophils and neutrophils. J Asthma. 2017;54(2):116-124.

80. Schimmer AD. Inhibitor of apoptosis proteins: translating basic knowledge into clinical practice. Cancer Res. 2004;64(20):7183-7190.

81. Wu S, Zhang YG, Lu R, et al. Intestinal epithelial vitamin D receptor deletion leads to defective autophagy in colitis. Gut. 2015;64(7):1082-1094.

82. Whelan KA, Merves JF, Giroux V, et al. Autophagy mediates epithelial cytoprotection in eosinophilic oesophagitis. Gut. 2017;66(7):1197-1207.

83. Hanash AM, Dudakov JA, Hua G, et al. Interleukin-22 protects intestinal stem cells from immune-mediated tissue damage and regulates sensitivity to graft versus host disease. Immunity. 2012;37(2):339-350.

84. Lindemans CA, Calafiore M, Mertelsmann AM, et al. Interleukin-22 promotes intestinal-stem-cell-mediated epithelial regeneration. Nature. 2015; 528(7583):560-564.

85. Winge MC, Ohyama B, Dey CN, et al. RAC1 activation drives pathologic interactions between the epidermis and immune cells. J Clin Invest. 2016; 126(7):2661-2677.

86. Parikh K, Zhou L, Somasundaram R, et al. Suppression of p21Rac signaling and increased innate immunity mediate remission in Crohn's disease. Sci Trans/ Med. 2014;6(233):233ra53.

87. Oberoi TK, Dogan T, Hocking JC, et al. IAPs regulate the plasticity of cell migration by directly targeting Rac1 for degradation. EMBO J. 2012;31(1): 14-28.

88. Cadwell K, Liu JY, Brown SL, et al. A key role for autophagy and the autophagy gene Atg16l1 in mouse and human intestinal Paneth cells. Nature. 2008; 456(7219):259-263.

89. Gutierrez MG, Saka HA, Chinen I, et al. Protective role of autophagy against Vibrio cholerae cytolysin, a pore-forming toxin from V. cholerae. Proc Natl Acad Sci USA. 2007;104(6):1829-1834. 